\title{
A gas chromatograph for quantification of peroxycarboxylic nitric anhydrides calibrated by thermal dissociation cavity ring-down spectroscopy
}

\author{
T. W. Tokarek, J. A. Huo, C. A. Odame-Ankrah, D. Hammoud, Y. M. Taha, and H. D. Osthoff \\ Department of Chemistry, University of Calgary, Calgary, Alberta T2N 1N4, Canada
}

Correspondence to: H. D. Osthoff (hosthoff@ucalgary.ca)

Received: 16 April 2014 - Published in Atmos. Meas. Tech. Discuss.: 13 June 2014

Revised: 11 August 2014 - Accepted: 12 August 2014 - Published: 1 October 2014

\begin{abstract}
The peroxycarboxylic nitric anhydrides (PANs, molecular formula: $\left.\mathrm{RC}(\mathrm{O}) \mathrm{O}_{2} \mathrm{NO}_{2}\right)$ can readily be observed by gas chromatography (PAN-GC) coupled to electron capture detection. Calibration of a PAN-GC remains a challenge, because the response factors differ for each of the PANs, and because their synthesis in sufficiently high purity is non-trivial, in particular for PANs containing unsaturated side chains. In this manuscript, a PAN-GC and its calibration using diffusion standards, whose output was quantified by blue diode laser thermal dissociation cavity ringdown spectroscopy (TD-CRDS), are described. The PANGC peak areas correlated linearly with total peroxy nitrate $(\Sigma \mathrm{PN})$ mixing ratios measured by TD-CRDS $(r>0.96)$. Accurate determination of response factors required the concentrations of PAN impurities in the synthetic standards to be subtracted from $\Sigma$ PN. The PAN-GC and its TD-CRDS calibration method were deployed during ambient air measurement campaigns in Abbotsford, BC, from 20 July to $5 \mathrm{Au}$ gust 2012, and during the Fort McMurray Oil Sands Strategic Investigation of Local Sources (FOSSILS) campaign at the AMS13 ground site in Fort McKay, AB, from 10 August to 5 September 2013. The PAN-GC limits of detection for PAN, PPN, and MPAN during FOSSILS were 1, 2, and 3 pptv, respectively. For the Abbotsford data set, the PAN-GC mixing ratios were compared, and agreed with those determined in parallel by thermal dissociation chemical ionization mass spectrometry (TD-CIMS). Advantages and disadvantages of the PAN measurement techniques used in this work and the utility of TD-CRDS as a PAN-GC calibration method are discussed.
\end{abstract}

\section{Introduction}

Peroxycarboxylic nitric anhydrides (PANs, also referred to as peroxyacyl nitrates) are important trace gas constituents of the troposphere (Roberts, 1990, 2007; Altshuller, 1993). PANs are formed as byproducts in the same photochemistry between $\mathrm{NO}_{\mathrm{x}}$ and volatile organic compounds (VOCs) that produces ozone $\left(\mathrm{O}_{3}\right)$ and photochemical smog; they are therefore good chemical markers of the types of VOCs involved in the $\mathrm{O}_{3}$ formation process (Roberts, 2007). Figure 1 shows examples of the most abundant PANs that have been found in the troposphere. Peroxyacetic nitric anhydride (PAN, molecular formula: $\mathrm{CH}_{3} \mathrm{C}(\mathrm{O}) \mathrm{O}_{2} \mathrm{NO}_{2}$; this is often referred to by its non-IUPAC name peroxyacetyl nitrate) is generally the most abundant PAN species, because its main precursor, acetaldehyde, is an oxidation product of many VOCs. Peroxypropionic nitric anhydride (PPN) is derived from propanal, and is generally regarded as an anthropogenic pollution tracer, whereas peroxymethacrylic nitric anhydride (MPAN), which in ambient air is formed from methacrolein (an isoprene oxidation product), is a tracer of the oxidation of biogenic VOCs. Peroxyacrylic nitric anhydride (APAN, originally referred to as vinyl PAN; Grosjean et al., 1994) is formed from acrolein (a propylene or butadiene oxidation product), and is regarded as a tracer of petrochemical VOC oxidation chemistry (Roberts et al., 2001, 2003; Tanimoto and Akimoto, 2001). In high concentrations, PANs are lachrymators, and are toxic to plants (Horvath et al., 1986; Kleindienst, 1994). Furthermore, PANs are considered $\mathrm{NO}_{\mathrm{x}}$ reservoir species, because they are longer lived than $\mathrm{NO}_{\mathrm{x}}$ $\left(\equiv \mathrm{NO}+\mathrm{NO}_{2}\right)$ and generate $\mathrm{NO}_{2}$ when they decompose (Kirchner et al., 1999). Chemical transport models indicate 


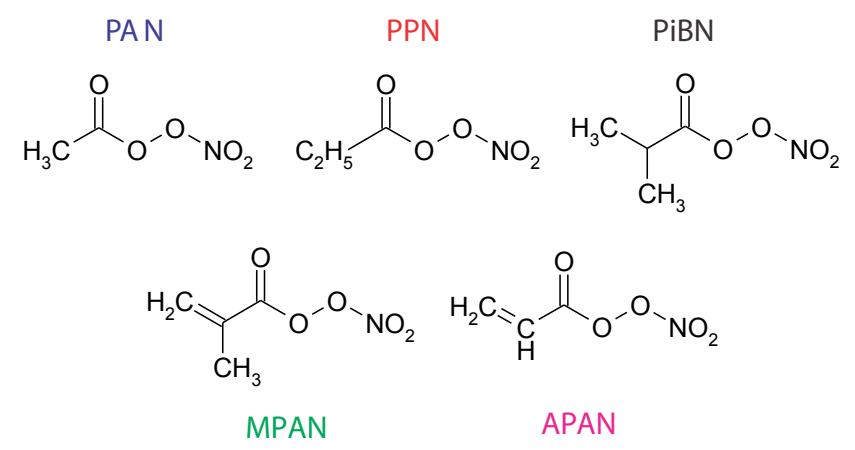

Figure 1. Molecular structures of common peroxycarboxylic nitric anhydrides. PAN = peroxyacetic, $\mathrm{PPN}=$ peroxypropionic, $\mathrm{PiBN}=$ peroxyisobutanoic,$\quad \mathrm{MPAN}=$ peroxymethacryloyl, and APAN $=$ peroxyacryloyl nitric anhydride.

that PANs can carry $\mathrm{NO}_{\mathrm{x}}$ over long distances and affect photochemical $\mathrm{O}_{3}$ production in remote regions (Fischer et al., 2010; Pandey Deolal et al., 2013). Due to its relatively long lifetime, PAN is also often the most abundant "odd nitrogen", or $\mathrm{NO}_{\mathrm{y}}\left(\equiv \mathrm{NO}_{\mathrm{x}}+\Sigma \mathrm{PAN}+\Sigma \mathrm{AN}+\mathrm{HNO}_{3}\right.$ $\left.+\mathrm{HONO}+\mathrm{NO}_{3}+2 \mathrm{~N}_{2} \mathrm{O}_{5}+\mathrm{ClNO}_{2}+\ldots\right)$, species in the middle to upper troposphere, at high latitudes, and in biomass burning plumes (Stroud et al., 2003; Alvarado et al., 2010).

Over the years, a variety of techniques to quantify PAN mixing ratios in ambient air have been developed. A widely used, mature, robust, and sensitive technique is gas chromatography with capillary columns and electron capture detection (e.g., Darley et al., 1963; Blanchard et al., 1990; Schrimpf et al., 1995; Williams et al., 2000; VolzThomas et al., 2002; Flocke et al., 2005); this measurement technique is referred to as PAN-GC in this manuscript. A relatively new and increasingly popular technique is thermal dissociation chemical ionization mass spectrometry (TDCIMS). In this technique, the PANs are dissociated in a heated inlet to their corresponding peroxyacyl radicals and detected, following electron transfer reaction with an iodide reagent ion, as their corresponding carboxylate anions (Slusher et al., 2004). Measurement of PANs using TD-CIMS in ambient air, however, is not straightforward, as there are matrix effects and interferences to consider (Zheng et al., 2011; Mielke and Osthoff, 2012; Phillips et al., 2013). Accurate measurements of MPAN are particularly challenging, because TD-CIMS is relatively insensitive to MPAN, and because ions other than methacrylate $\left(\mathrm{CH}_{2}=\mathrm{C}\left(\mathrm{CH}_{3}\right) \mathrm{CO}_{2}^{-}\right)$, e.g., trifluoromethoxy anions $\left(\mathrm{CF}_{3} \mathrm{O}^{-}\right.$, generated from $\mathrm{CF}_{3} \mathrm{OH}$ that outgasses from Teflon tubing) and crotonate $\left(\mathrm{CH}_{3} \mathrm{CH}=\mathrm{CHCO}_{2}^{-}\right.$, generated from peroxycrotonyl nitrate, CPAN), interfere at $m / z 85$ (Zheng et al., 2011; Mielke and Osthoff, 2012). PANs have also been quantified by proton transfer mass spectrometry (Hansel and Wisthaler, 2000; Hastie et al., 2010) and by quantifying the $\mathrm{NO}_{2}$ generated from their thermal dissociation (usually by the difference relative to background $\mathrm{NO}_{2}$ ) using luminol chemiluminescence (CL) (Nikitas et al., 1997; Marley et al., 2004), laser-induced fluorescence (LIF) (Day et al., 2002; Wooldridge et al., 2010), or cavity ring-down spectroscopy (CRDS) (Paul and Osthoff, 2010; Paul et al., 2009). In spite of the development of these new PAN measurement techniques, PAN-GCs remain attractive because of their relative simplicity, compactness, robustness, good sensitivity, and lack of interferences, properties that are desirable for long-term and unattended operations (e.g., Mills et al., 2007; Zhang et al., 2009; Fischer et al., 2010; Zhang et al., 2012).

The key challenge in the measurement of PANs by PAN$\mathrm{GC}$ is calibration. The response factors of PAN-GC instruments (and, incidentally, of TD-CIMS instruments) are different for each of the PAN compounds; hence, each PAN requires individual calibration (Flocke et al., 2005). Diffusion sources whose outputs are quantified by $\mathrm{NO}_{\mathrm{y}} \mathrm{CL}$ instruments are commonly used for this purpose. This, however, requires syntheses of PAN standards in high purity. The syntheses of pure MPAN and APAN samples are particularly challenging, because both molecules contain carbon-carbon double bonds in their side chain that are prone to unwanted side reactions. In their case, a preparative-scale GC is often used to discriminate the PAN standard from other nitrogen oxide-containing impurities (Flocke et al., 2005). Another challenge in the calibration using diffusion sources is sample storage and delivery, as PANs are explosive in pure form and are prone to thermal decomposition; as a result, standards are usually stored in a non-polar solvent (such as tridecane) at cold temperatures, e.g., in vials partially immersed in an icewater bath (Gaffney et al., 1984). Photochemical sources, in which PANs are generated in situ, e.g., from photodissociation of dialkyl ketones in the presence of oxygen and a calibrated amount of $\mathrm{NO}_{\mathrm{x}}$, are an attractive alternative to diffusion standards, as they require neither cooling nor the transport and storage of toxic chemicals (Warneck and Zerbach, 1992; Grosjean et al., 1984; Flocke et al., 2005; Pätz et al., 2002; Volz-Thomas et al., 2002; Emrich and Warneck, 2000; Furgeson et al., 2011). So far, photochemical sources have been limited to the generation of PANs with short saturated side chains, i.e., PAN, PPN, and peroxyisobutyric nitric anhydride (PiBN) (Furgeson et al., 2011).

In this manuscript, a recently assembled PAN-GC and its calibration for PAN, PPN, MPAN, and APAN using diffusion standards whose outputs were quantified by blue diode laser TD-CRDS are described. Calibration and ambient air data collected during measurement campaigns at ground sites in Abbotsford, BC, from 20 July to 5 August 2012, and near Fort McKay, AB, during the Fort McMurray Oil Sands Strategic Investigation of Local Sources (FOSSILS) campaign from 10 August to 5 September 2013, are presented. 


\section{Experimental}

\subsection{PAN-GC setup and operation}

The PAN-GC used in this work was a Varian 3380CP equipped with an ECD detector (model number 0200197201 ) that was converted to measure PANs in a similar fashion to that described by Fischer et al. (2010). A two-position sample valve (VICI Valco EHC10WE, $1 / 16^{\prime \prime} \times 0.40 \mathrm{~mm}$ with a microelectric actuator) and a sample loop constructed from polyether ether ketone (PEEK, VICI "Cheminert") were mounted inside the GC oven as shown in Fig. 2. A 10-port valve was used (in lieu of a 6-port valve) because it was the only valve on hand. The analytical column used was a medium polarity "megabore" column (Restek RTX-1701) with a $0.53 \mathrm{~mm}$ inner diameter (i.d.) and $1 \mu \mathrm{m}$ film thickness. Sample air was drawn through the sample loop using a miniature air compressor (McMaster-Carr $4404 \mathrm{~K} 15$ ) at a flow rate of 115 standard cubic centimeters per minute $(\mathrm{sccm})$ set by flow restriction. Ultrapure $\mathrm{He}$ (Scott-Marrin) was used as a carrier gas at a flow rate of $20 \mathrm{~mL} \mathrm{~min}^{-1}$ set using a needle valve and measured at the ECD exhaust. A van Deemter plot analysis (not shown) showed that the chromatographic height of a theoretical plate was at its minimum value at this carrier gas flow rate. The He regulator was connected to the GC via PEEK 1/8" outer diameter (o.d.) tubing (VICI) through a He-specific inline "triple trap" (Restek 22469) to remove hydrocarbons, oxygen, and moisture. The carrier gas was re-humidified by passing it over $50 \mathrm{~g} \mathrm{CuSO}_{4}$ pentahydrate $(99.995 \%$, Aldrich) contained in a stainless steel sample cylinder with $150 \mathrm{~cm}^{3}$ internal volume capped by a $2 \mu \mathrm{m}$ pore size in-line filter (Swagelok 316L-HDF4-150 and SS-4FW5-2). The presence of $\mathrm{H}_{2} \mathrm{O}$ has been reported to reduce chemical oncolumn losses of PAN compounds and to improve run-to-run reproducibility for periods of several months of continuous operation (Flocke et al., 2005). ECD-grade $\mathrm{N}_{2}$ (Praxair) was used as a make-up gas at a flow rate of $2.0 \mathrm{~mL} \mathrm{~min}^{-1}$.

Prior to making measurements, the ECD was heated for $24 \mathrm{~h}$ at its maximum temperature setting of $300^{\circ} \mathrm{C}$ under He flow to lower the background signal. Afterwards, the ECD was operated at its lowest possible temperature setting $\left(50^{\circ} \mathrm{C}\right)$ in constant current mode with the "FAST" $(50 \mathrm{~ms})$ time constant setting. The ECD signal voltage was digitized using a Universal Serial Bus (USB) 2.0 data acquisition module (Omega) connected to a laptop computer running software written in National Instrument's LAB VIEW 2010, which also controlled the main switching valve. The valve was set to the "fill sample loop" position (Fig. 2a) by default. Injections were automated (usually every 6 or $10 \mathrm{~min}$ ) and synchronized to the top of the hour by switching to the "sample to column" setting (Fig. 2b) for $30 \mathrm{~s}$.

During the Abbotsford campaign, the PAN-GC sampled from an inlet constructed from $1 / 4^{\prime \prime}(0.635 \mathrm{~cm})$ o.d. fluorinated ethylene propylene (FEP) Teflon tubing shared with a
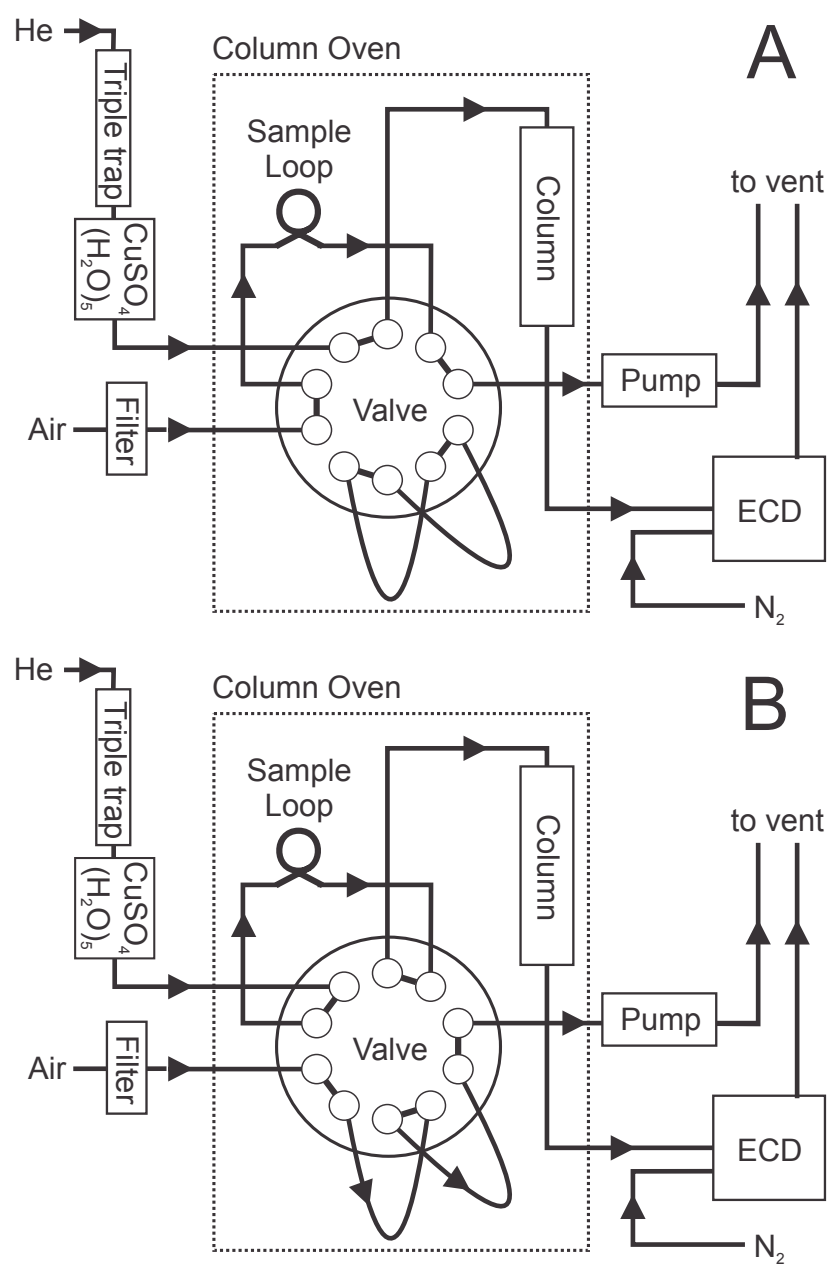

Figure 2. Schematic of the PAN-GC (items not to scale). (a) Fill sample loop (default). (b) Sample loop to column. See text for a detailed description.

commercial $\mathrm{O}_{3}$ UV absorption spectrometer (Thermo 49i) and sampled through a $1 \mu \mathrm{m}$ pore size Teflon filter in a polycarbonate filter holder (Pall Life Sciences). The passing efficiency of such a filter has been reported as $100 \%$ (Roberts et al., 2007), which was confirmed in laboratory tests. Ambient air samples were automatically injected onto the column once every $6 \mathrm{~min}$. The sample loop had an internal volume of $2.0 \mathrm{~mL}$, and the analytical column length was $20.41 \mathrm{~m}$. The column oven was set to a temperature of $+25^{\circ} \mathrm{C}$, but was occasionally higher in the afternoons as the trailer housing the instruments warmed up to above this temperature. At the beginning of the campaign (until 25 July, 16:00 local time), the ECD was operated with the "CAP" (480 pA) sensitivity setting and at a contact potential of $175 \mathrm{mV}$. The remaining data were collected using the (less sensitive) " $\mathrm{N}_{2}$ STD" (290 pA) setting. The detector voltages were digitized using a 14-bit data acquisition module (Omega USB-1408FS) at a sampling rate of $500 \mathrm{~Hz}$. 
For the FOSSILS campaign, the data acquisition board was upgraded to a 16-bit module (Omega USB-1608FS) operated at a sampling rate of $10 \mathrm{kHz}$. Data were box-car averaged to $20 \mathrm{~Hz}$ immediately after acquisition. The ECD was operated with the "CAP" $(480 \mathrm{pA})$ sensitivity setting at a contact potential of $400 \mathrm{mV}$. The analytical column was shortened to $10.5 \mathrm{~m}$, the sample loop volume reduced to $1.0 \mathrm{~mL}$, and the oven temperature set point was set to a temperature of $22^{\circ} \mathrm{C}$. Ambient air samples were automatically injected once every $10 \mathrm{~min}$. Partway through the FOSSILS campaign, the PAN-GC miniature air compressor pump failed. Sample air was then drawn through the sample loop using a $50 \mu \mathrm{m}$ critical orifice connected to a twin head diaphragm pump (KNF Neuberger N 026.1.2AT), which provided a flow rate of $15 \mathrm{sccm}$ as measured using a mass flow controller (MKS M100B), and which altered the PAN-GC response factors (see Sect. 3.3).

\subsection{Data reduction}

To determine chromatographic parameters, parameters of the Gaussian Eq. (1) were fitted to the observed peaks using a macro written in Igor Pro 6 (Wavemetrics).

$$
V=\frac{A}{\sqrt{2 \pi \sigma^{2}}} e^{\frac{-1}{2}\left(\frac{t-t_{0}}{\sigma}\right)^{2}}+V_{0}+m t
$$

In Eq. (1), $V$ is the signal voltage observed, $A$ and $\sigma$ are the peak area and its standard width, $t$ is the time since injection, $t_{0}$ the retention time, and $V_{0}$ and $m$ are the offset and slope of the background.

Chromatograms were smoothed in post-data acquisition processing using Igor Pro's built-in Savitzky-Golay algorithm (fourth order). For the Abbotsford campaign, a width of $\sim 2$ s, i.e., 1001 data points, was chosen, whereas for the FOSSILS campaign, a width of four standard peak half widths ( $\sim 4 \sigma$; see Tables 1 or 2 for typical $\sigma$ values) was used for each peak, i.e., PAN peaks were smoothed over 69 data points, PPN over 235 points, and MPAN over 399 points.

To ensure that the fitting macro converged onto the "correct" local minimum (i.e., fitted the peak and did not attempt to fit a trend in the background or the oxygen peak), only the region near a peak $\left(t_{0} \pm 8 \sigma\right)$ was fitted. The fits were performed in stages: the first iteration constrained $t_{0}$, $\sigma$, and $A$ to values from the preceding chromatogram (or to values that were entered manually) to determine the baseline (which shifted often between chromatograms). These constraints were lifted sequentially in subsequent fits until the peak was described accurately by Eq. (1). For PPN and MPAN, knowledge of the relative retention times and peak widths from calibration runs were used in the first fit iteration; i.e., $t_{0}$ and $\sigma$ were estimated from their average values relative to those of the PAN peak (in the same chromatogram) observed in calibration runs. Subsequent fit iterations were the same as for PAN.
Table 1. Parameters of Eq. (1) fitted to the top three chromatograms in Fig. 5a. The fit uncertainties are those estimated using built-in algorithms in the Igor Pro 6 software package. The uncertainty stated for $\Sigma \mathrm{PN}$ is the $1 \sigma$ measurement precision. Concentrations of impurities were not determined.

\begin{tabular}{llll}
\hline $\begin{array}{l}\text { Parameter } \\
\text { (unit) }\end{array}$ & PAN & APAN & PPN \\
\hline$t_{0}(\mathrm{~s})$ & $76.379 \pm 0.003$ & $133.570 \pm 0.002$ & $160.75 \pm 0.010$ \\
$\sigma(\mathrm{s})$ & $1.238 \pm 0.004$ & $1.882 \pm 0.003$ & $2.15 \pm 0.012$ \\
$V_{0}(\mathrm{mV})^{*}$ & $250.5 \pm 1.4$ & $7.3 \pm 4.0$ & $164.4 \pm 1.8$ \\
$m\left(\mathrm{mV} \mathrm{s}^{-1}\right)$ & $0.017 \pm 0.017$ & $0.72 \pm 0.03$ & $0.105 \pm 0.011$ \\
$A(\mathrm{mV} \mathrm{s})$ & $350.6 \pm 1.1$ & $1177.0 \pm 2.2$ & $194.6 \pm 1.2$ \\
$\Sigma \mathrm{PN}(\mathrm{ppbv})$ & $0.53 \pm 0.16$ & $2.5 \pm 0.2$ & $0.43 \pm 0.13$ \\
\hline
\end{tabular}

* Vertical offsets were modified in Fig. 5a to minimize overlap and improve clarity.

\subsection{Synthesis of standards}

PAN standards were synthesized following procedures communicated to us by J. Roberts (personal communication, 2009) that are based on those described in earlier publications (Williams et al., 2000; Bertman and Roberts, 1991). Reagents were purchased from Sigma-Aldrich and used as received. PAN, PPN, and MPAN were synthesized from their respective acid anhydrides, which were oxidized using $\mathrm{H}_{2} \mathrm{O}_{2}$ to the peroxyacids and reacted with strong sulfuric and nitric acid. Workup and sample storage were as described earlier (Mielke and Osthoff, 2012). APAN was synthesized from acryloyl chloride $\left(\mathrm{CH}_{2} \mathrm{CHC}(\mathrm{O}) \mathrm{Cl}\right)$, as it was commercially available, whereas acrylic anhydride was not. Briefly, $8.0 \mathrm{~mL}$ of acryloyl chloride $\left(\mathrm{CH}_{2} \mathrm{CHC}(\mathrm{O}) \mathrm{Cl}\right)$ were placed in an icecold $100 \mathrm{~mL}$ round-bottom flask containing a magnetic stirrer, to which $5.0 \mathrm{~mL}$ of cold $50 \% \mathrm{H}_{2} \mathrm{O}_{2}$ were added drop wise. After $2 \mathrm{~h}, 20.0 \mathrm{~mL}$ of cold tridecane were added, followed by slow addition of $5.0 \mathrm{~mL}$ of cold concentrated sulfuric acid and slow drop-wise addition of $6.0 \mathrm{~mL}$ cold concentrated nitric acid. After $15 \mathrm{~min}$, the organic and aqueous layers were separated in a $125 \mathrm{~mL}$ separatory funnel. The organic layer was washed three times using $50 \mathrm{~mL}$ of cold deionized water, dried over $\mathrm{MgSO}_{4}$, and filtered through a cotton swab. Small aliquots of APAN in tridecane solution were stored in $2.0 \mathrm{~mL}$ polypropylene centrifuge tubes (VWR) in a freezer prior to use.

\subsection{Thermal dissociation cavity ring-down spectroscopy}

The University of Calgary blue diode laser TD-CRDS has been described earlier (Paul and Osthoff, 2010). Briefly, the TD-CRDS contains multiple sample channels operated at different inlet temperatures, and differentiates between $\mathrm{NO}_{2}$ sampled at ambient temperature and $\mathrm{NO}_{2}+$ total peroxyacyl nitrates $(\Sigma \mathrm{PN})$ sampled at an inlet temperature of $250^{\circ} \mathrm{C}$. $\mathrm{NO}_{2}$ is quantified by its optical absorption at $405 \mathrm{~nm}$. $\Sigma \mathrm{PN}$ is quantified by the difference relative to the ambient temperature channel. During the FOSSILS campaign, the blue diode laser TD-CRDS was operated with the "linear regression of 
Table 2. Parameters of Eq. (1) fitted to the chromatograms in Fig. 5b, acquired during the FOSSILS 2013 field campaign. The fit uncertainties are those estimated using built-in algorithms in the Igor Pro 6 software package. The uncertainty stated for $\Sigma \mathrm{PN}$ is the $1 \sigma$ measurement precision.

\begin{tabular}{llll}
\hline $\begin{array}{l}\text { Parameter } \\
\text { (unit) }\end{array}$ & PAN & PPN & MPAN \\
\hline$t_{0}(\mathrm{~s})$ & $115.080 \pm 0.002$ & $243.820 \pm 0.002$ & $408.820 \pm 0.002$ \\
$\sigma(\mathrm{s})$ & $1.667 \pm 0.002$ & $2.946 \pm 0.002$ & $4.912 \pm 0.002$ \\
$V_{0}(\mathrm{mV})^{*}$ & $118.9 \pm 2.1$ & $64.3 \pm 1.0$ & $22.06 \pm 0.34$ \\
$m\left(\mathrm{mV} \mathrm{s}^{-1}\right)$ & $0.125 \pm 0.018$ & $0.0446 \pm 0.004$ & $0.0167 \pm 0.0008$ \\
$A(\mathrm{mV} \mathrm{s})$ & $1430.5 \pm 1.8$ & $1432.1 \pm 1.0$ & $1694.9 \pm 0.7$ \\
$\Sigma \mathrm{PN}(\mathrm{ppbv})$ & $2.43 \pm 0.20$ & $2.66 \pm 0.21$ & $2.38 \pm 0.19$ \\
Impurities (pptv) & n/a & PAN: 41 & PAN: 610; PPN: 29 \\
\hline * Vertical offsets were modified in Fig. 5b to minimize overlap and improve clarity.
\end{tabular}

the sum" (LRS) algorithm (Everest and Atkinson, 2008; Taha et al., 2013) and at a diode laser pulse repetition rate of $1 \mathrm{kHz}$.

\subsection{Chemical ionization mass spectrometry}

The iodide ion TD-CIMS and its operation have also been described in earlier publications (Mielke et al., 2011, 2013; Mielke and Osthoff, 2012). During the Abbotsford campaign and in laboratory experiments, it was operated in TD mode (i.e., with an inlet heated to $190^{\circ} \mathrm{C}$ ) with a humidified reaction chamber. Background counts arising from peroxyacids (Furgeson et al., 2011; Phillips et al., 2013) were determined by periodically (every $30 \mathrm{~min}$ ) flooding the inlet with a high concentration of NO delivered from a $0.1 \% \mathrm{NO}$ in $\mathrm{N}_{2}$ cylinder (Praxair). The background count data were interpolated and subtracted from the ambient ion counts. The TD-CIMS method is prone to interferences arising from proton exchange of acetate (which is generated from PAN) with organic acids and from titration of the peroxyacyl radicals by $\mathrm{NO}$ and $\mathrm{NO}_{2}$ (Mielke and Osthoff, 2012). In previous work, the titration by $\mathrm{NO}_{\mathrm{x}}$ was tracked by adding ${ }^{13} \mathrm{C}-\mathrm{PAN}$ as an internal standard to the inlet. However, the photochemical source that had been used in earlier experiments to deliver ${ }^{13} \mathrm{C}-\mathrm{PAN}$ was not used in Abbotsford, because it had been contaminated (with $\mathrm{Cl}_{2}$ ) immediately prior to the campaign. To account for matrix effects arising from titration of the peroxyacyl radicals by $\mathrm{NO}$ and $\mathrm{NO}_{2}$ in the field, ambient ion counts were multiplied by a factor of $\exp \left(k_{\mathrm{NO}} \times[\mathrm{NO}]+k_{\mathrm{NO}_{2}} \times\left[\mathrm{NO}_{2}\right]\right)$, where [NO] and $\left[\mathrm{NO}_{2}\right]$ are mixing ratios observed by a commercial $\mathrm{NO} / \mathrm{NO}_{\mathrm{y}} \mathrm{CL}$ instrument (Thermo 42i) and the University of Calgary CRDS, respectively, and $k_{\mathrm{NO}}$ and $k_{\mathrm{NO}_{2}}$ are empirical constants. The values for PAN $\left(k_{\mathrm{NO}}=0.0513 \mathrm{ppbv}^{-1}\right.$ and $k_{\mathrm{NO}_{2}}=0.0203 \mathrm{ppbv}^{-1}$ ) were determined from a comparison of our group's TD-CIMS PAN data with PAN measured by NOAA's PAN-GC during the Calnex-LA campaign (Mielke et al., 2013). The values for PPN $\left(k_{\mathrm{NO}}=\right.$ $0.118 \mathrm{ppbv}^{-1}$ and $k_{\mathrm{NO}_{2}}=0.033 \mathrm{ppbv}^{-1}$ ) were taken from Mielke and Osthoff (2012). During FOSSILS, the CIMS was operated with an ambient-temperature inlet, and PANs were not quantified by TD-CIMS.

\subsection{Inlet setup and in-field calibrations}

Figure 3 shows a sketch of the inlet setup deployed in the field. All instruments were sampled from a common inlet manifold and were "zeroed" periodically using automated switching valves, usually in between PAN-GC injections. During the Abbotsford campaign, a flow of $\sim 20$ standard liters per minute (slpm) of ultrapure ("zero" grade) air was delivered from gas cylinders (Praxair) via a 30 slpm capacity mass flow controller (MFC, Celerity) and a two-way normally closed solenoid valve (Galtek 203-1414-215). During FOSSILS, the instruments were zeroed using a combination of ambient and exhaust air that was scrubbed with a combination of activated charcoal (Whatcom) and potassium permanganate (Purafil Select). Occasionally, zero air from a cylinder was used instead. The only difference observed between the scrubbed air and the zero air was the higher humidity of the former.

The PAN-GC was calibrated using diffusion sources that each contained a PAN standard of interest whose output was quantified by TD-CRDS. For in-field calibration runs, the gas stream containing the PAN standard was delivered to the inlet manifold in a similar fashion as described for $\mathrm{N}_{2} \mathrm{O}_{5}$ by Odame-Ankrah and Osthoff (2011). Briefly, a 1/4" o.d. FEP Teflon tube was conditioned for $30 \mathrm{~min}$ to $1 \mathrm{~h}$, with the output of the diffusion standard (which was kept in a glass vessel in an ice-water bath) diluted in typically $20 \mathrm{sccm}$ zero air. This tube was teed into the line delivering zero (or scrubbed) air to the main inlet (Fig. 3) and connected, via a remotely controlled normally open two-way valve (Cole Parmer 0154010), to a waste line evacuated by a diaphragm pump (KNF Neuberger N026.1.2AT) whose flow rate was throttled using a $50 \mu \mathrm{m}$ critical orifice (Lennox Laser). A similar setup was also used to deliver a flow containing high concentrations of NO to zero the TD-CIMS.

A typical sequence of how an individual calibration point was obtained is shown in Fig. 4. Prior to and following the PAN-GC injection, the TD-CRDS and NO / $\mathrm{NO}_{\mathrm{y}} \mathrm{CL}$ instruments were zeroed (shown with a gray underlay) by flooding the inlet with scrubbed or zero air. About $2 \mathrm{~min}$ prior to the GC injection, the standard was delivered to the instruments by closing the two-way valve. Following the PAN-GC injection, the other instruments were zeroed again. The bracketing of the calibration sequence by "zeroes" is required to make accurate measurements by TD-CRDS, which is inherently a measurement of difference, i.e., of ring-down time constants in the absence and presence of the optical absorber $\left(\mathrm{NO}_{2}\right.$ in this case).

During the Abbotsford campaign, a PAN calibration point was obtained typically once (sometimes twice) per day (for a total of 16 points). In addition, 6 calibration points were collected for PPN. During FOSSILS, calibration points were 


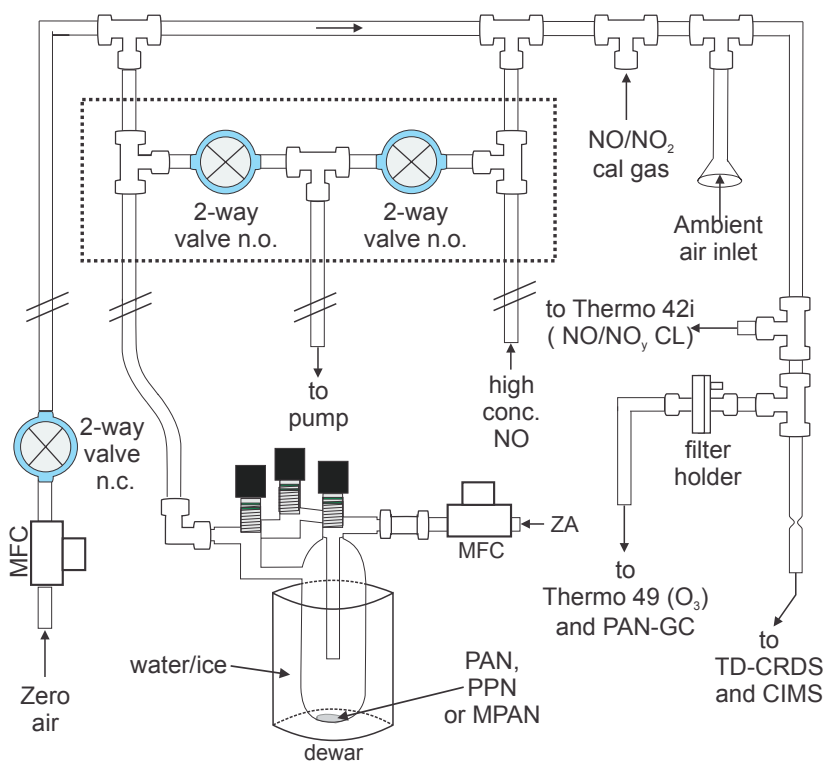

Figure 3. Schematic of the inlet and calibration setup used during the Abbotsford 2012 and FOSSILS 2013 field campaigns. $\mathrm{MFC}=$ mass flow controller, $\mathrm{CL}=$ chemiluminescence, n.o. $=$ normally open, n.c. $=$ normally closed.

collected approximately daily for PAN (34 points in total), PPN (21 points), and MPAN (26 points). The PAN standards were kept in separate glass traps that were stored in ice/water baths between use. Each diffusion source was loaded only once at the beginning of each campaign, and there was no evidence of sample decomposition. The response factor for APAN was determined after the FOSSILS campaign.

The $\mathrm{NO} / \mathrm{NO}_{\mathrm{y}} \mathrm{CL}$ instrument was calibrated daily (against CRDS) by sampling $\mathrm{NO}$ and/or $\mathrm{NO}_{2}$, generated using an NO standard gas cylinder (Scott Marrin) to which up to a stoichiometric amount of $\mathrm{O}_{3}$ was added, generated by passing oxygen from a gas cylinder (Praxair) past a $254 \mathrm{~nm} \mathrm{Hg}$ lamp. The $\mathrm{NO}_{\mathrm{x}}$ standard was delivered to the main inlet via a separate $1 / 4^{\prime \prime}$ o.d. Teflon tube connected to the zero air line; delivery was automated using a two-way normally open valve.

\subsection{Ambient air measurement locations}

The first set of ambient air measurements was conducted at a routine monitoring site located east of Abbotsford International Airport (International Air Transport Association (IATA) airport code YXX) at latitude $49.0212^{\circ} \mathrm{N}$ and longitude $-122.3267^{\circ} \mathrm{W}, \sim 60 \mathrm{~m}$ above sea level (a.s.l.). The city of Abbotsford (population 140 000) is located in the lower Fraser Valley, which is prone to episodes of poor air quality, i.e., exceedances of $\mathrm{O}_{3}$ and particulate matter (PM) air quality standards. These occur in part because the topography facilitates stagnation periods and trapping of airborne pollutants near the surface, and because of continuously

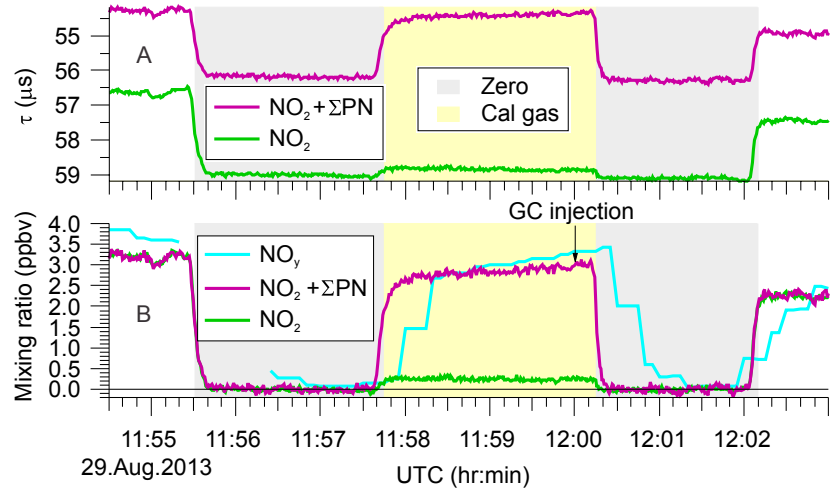

Figure 4. Typical calibration sequence. (a) Time series of ringdown time constants. (b) Time series of TD-CRDS and $\mathrm{NO}_{\mathrm{y}}$ mixing ratios. The instruments were "zeroed" at 11:55:30 UTC. PPN was added at $\sim 11: 57: 40$ UTC. The GC was injected at noon (the chromatogram is shown in Fig. 5b). Immediately after the injection, the instruments were zeroed again. The $\mathrm{NO}_{\mathrm{y}}$ signal was not adjusted for its slow response to concentration changes in this figure.

increasing emissions from urban, suburban, agricultural and marine sources that include the city and port of Vancouver (Vingarzan and Li, 2006; Ainslie and Steyn, 2007). The measurement site itself was surrounded by raspberry fields and impacted by emissions from nearby agricultural operations (such as chicken farms) and traffic on nearby highways and secondary roads.

The second set of ambient air measurements (the FOSSILS campaign) was conducted at the AMS13 (formerly "Syncrude") ground site near Fort McKay, AB, at latitude $57.1492^{\circ} \mathrm{N}$ and longitude $-111.6422^{\circ} \mathrm{W}$, and at $\sim 270 \mathrm{~m}$ a.s.l. This site is surrounded by boreal forest, and is occasionally impacted by emissions from nearby oil sand surface mining operations, for example, the Syncrude mine $\sim 4.5 \mathrm{~km}$ to the $\mathrm{S}$, the Suncor mine $\sim 20 \mathrm{~km}$ to the SE, Canadian Natural Resources Ltd. (CNRL) operations $\sim 13 \mathrm{~km}$ to the NNW, and the Shell mine $\sim 8 \mathrm{~km}$ to the NNE.

\section{Results}

\subsection{Gas chromatography of PAN standards}

Figure 5a shows sample chromatograms of PAN, PPN, and APAN standards plus a mixture of all three (all in zero air) collected in the laboratory after the FOSSILS campaign. Figure $5 \mathrm{~b}$ shows sample chromatograms of PAN, PPN, and MPAN standards (in a background of scrubbed air) acquired in the field during the FOSSILS campaign. Following the initial off-scale $\mathrm{O}_{2}$ peak, the four PAN standards elute as baseline resolved peaks with relative retention times consistent with those reported by Tanimoto and coworkers for a RTX1701 column (Tanimoto et al., 1999; Tanimoto and Akimoto, 2001). Tables 1 and 2 summarize the fits of parameters 


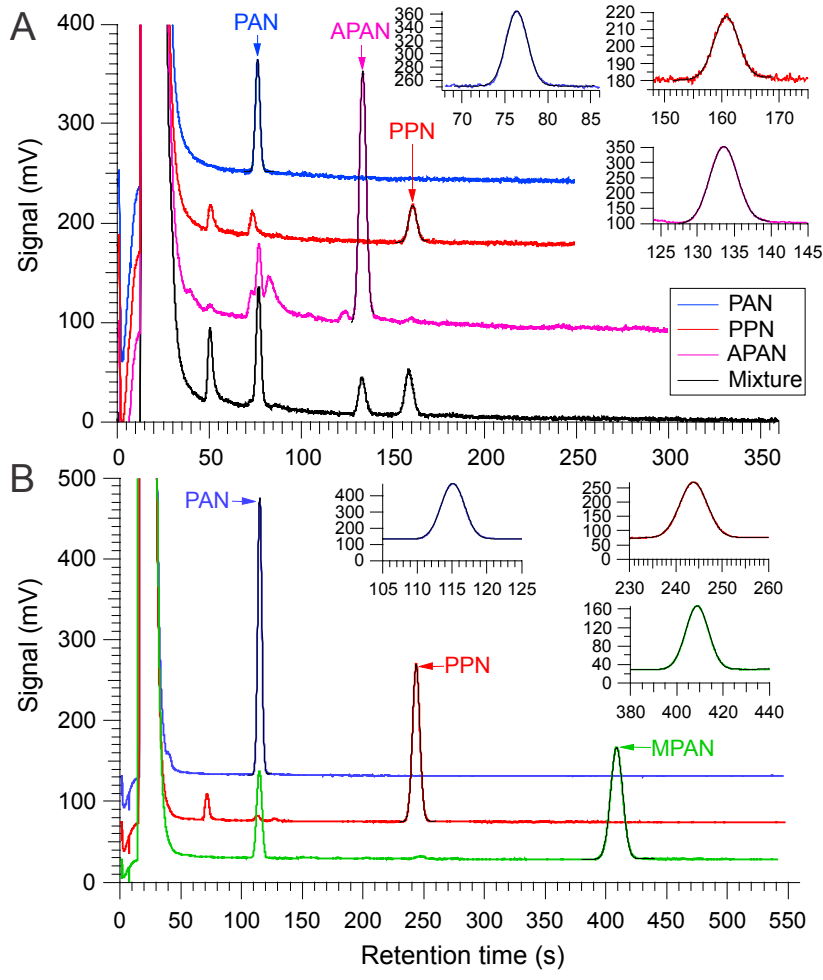

Figure 5. Sample chromatograms (vertically offset for clarity) of PAN, PPN, APAN, and MPAN standards on a $10.4 \mathrm{~m}$ RTX-1701 column at a He flow rate of $20 \mathrm{~mL} \mathrm{~min}^{-1}$. (a) Chromatograms of standards acquired in the laboratory at a column oven temperature of $27^{\circ} \mathrm{C}$. (b) Chromatograms of standards acquired during the FOSSILS 2013 field study at an oven temperature of $22^{\circ} \mathrm{C}$. The fits of expression (1) to the observed peaks are superimposed as black traces.

in Eq. (1) to the chromatograms presented in Fig. 5. A comparison of the fits and observations are shown as inserts in Fig. 5. The PANs eluted as essentially perfect Gaussians. As a result, the retention times, the peak widths, and the areas were determined with high precision. In contrast, peaks not associated with PANs (i.e., alkyl nitrates and other impurities) exhibited tailing, and were not quantified in this work.

\subsection{Impurities in the PAN standards}

The chromatograms in Fig. 5 show that the PPN, MPAN, and APAN standards each contained a small amount of PAN. This impurity was observed in all synthetic batches analyzed in this work. The chromatogram of APAN in Fig. 5a and to a lesser extent that of MPAN in Fig. 5b contained PPN as a result of memory effects within the calibration line; we found that PPN strongly absorbed and only very slowly desorbed from Teflon tubing. One Teflon fitting exposed to high PPN concentrations emitted PPN months after the exposure, in spite of several hour-long wash cycles in sonicated hot water.
In the field, this memory effect was minimized (but could not be completely eliminated) by flushing the calibration tubing with $20 \mathrm{sccm}$ zero air between calibrations. Because all PANs contribute to the $\Sigma$ PN signal observed by TD-CRDS, their mixing ratios need to be subtracted for accurate calibrations (see Sect. 3.3).

The standard chromatograms also contained traces of other impurities. For example, the shoulder on the $\mathrm{O}_{2}$ peak in the PAN standard chromatogram (blue trace in Fig. 5b, retention time $41 \mathrm{~s}$; not resolved in Fig. 5a) is likely methyl nitrate. A tailing peak in the PPN standard chromatogram (retention time $51 \mathrm{~s}$ in the red trace in Fig. 5a; $71 \mathrm{~s}$ in Fig. 5b) is likely ethyl nitrate, as it has the same retention time as an authentic ethyl nitrate sample.

The APAN standard chromatogram (purple trace in Fig. 5a) contains several unidentified peaks with retention times at $39,73,83,122,159,242$, and $284 \mathrm{~s}$. To gain insights into the identity of these unknown peaks, the iodide ion chemical ionization mass spectra of an APAN standard (Fig. 6, red color) and of background room air (Fig. 6, blue color) were recorded. The acrylate anion originating from APAN appears at $m / z 71$ as the dominant product ion in the mass spectrum. In addition, nitryl chloride $\left(\mathrm{ClNO}_{2}\right)$ is observed as its iodide cluster ion at $m / z 208$ and $m / z 210$ and as its characteristic fragments at $m / z 162$ and $m / z 164$ $\left(\mathrm{ICl}^{-}\right)$and $m / z 35$ and $m / z 37\left(\mathrm{Cl}^{-}\right)$(McNeill et al., 2006; Mielke et al., 2011; Osthoff et al., 2008). The amount of $\mathrm{ClNO}_{2}$ evaporating from the tridecane solution was greater than that of APAN (1.5 ppbv vs. $0.8 \mathrm{ppbv}$ ), such that its presence would pose a significant interference if the instruments were calibrated using $\mathrm{NO}_{\mathrm{y}} \mathrm{CL}$. The APAN standard mass spectrum also contains $m / z 59$ (acetate, produced from PAN) as the third-most abundant compound ( $\sim 9 \%$ relative to APAN), which is consistent with the GC chromatogram in Fig. 5a. In addition, there are enhancements at $m / z 62$ (nitrate) and smaller enhancements at $m / z 73$ (propionate, from PPN, $\sim 7 \%$ relative to APAN), $m / z 75(\sim 3 \%$ relative to $m / z 71$ ), $m / z 105, m / z 107$, and $m / z 160$ (unidentified). The counts at $m / z 75$ are possibly from $\mathrm{HOCH}_{2} \mathrm{COO}^{-}$, which is the anion derived from $\mathrm{HOCH}_{2} \mathrm{COONO}_{2}$, HPAN, or from its isomer $\mathrm{CH}_{3} \mathrm{OCOO}^{-}$, which is the anion derived from $\mathrm{CH}_{3} \mathrm{OC}(\mathrm{O}) \mathrm{OONO}_{2}$, MoPAN; the latter is believed to be more stable at room temperature (Zheng et al., 2011), but is less likely to have formed during APAN synthesis. The relative peak intensities at $m / z 105$ and $m / z, 107$ suggest a $\mathrm{Cl}$-containing product, possibly $\mathrm{ClCH}=\mathrm{CHCOO}^{-}$, which may have been generated from $\mathrm{ClCH}=\mathrm{CHCOONO}_{2}$. The ion counts at $m / z 105$ are $\sim 2 \%$ relative to $m / z 71$.

\subsection{PAN-GC response factors}

The response factors of the PAN-GC were sufficiently stable between days, such that conventional calibration plots, i.e., plots of PAN-GC peak areas against $\Sigma \mathrm{PN}$ mixing ratios, could be constructed using all calibration points collected. 
Table 3. Response factors of the PAN-GC (in $\mathrm{mVsppbv}^{-1}$ ) in the CAP and the $\mathrm{N}_{2}$ STD sensitivity setting, and of the TD-CIMS (in $\mathrm{Hz} \mathrm{ptv}^{-1}$ ) for PAN and PPN during the Abbotsford campaign. TD-CIMS counts were normalized to $1 \times 10^{6}$ reagent ion counts at $m / z$ 127. $\mathrm{RF}_{\mathbf{u}}$ is the uncorrected response factor, $\mathrm{RF}_{\mathrm{cor}}$ is the response factor corrected for PAN impurities contributing to the $\Sigma \mathrm{PN}$ signal, RSD is the relative standard deviation, $r$ is the $r$ value of the calibration plot, $n$ is the number of calibration runs, and nd means not determined.

\begin{tabular}{lllllll}
\hline Parameter or reference & PAN $(\mathrm{CAP})$ & $\mathrm{PPN}(\mathrm{CAP})$ & PAN $\left(\mathrm{N}_{2}\right.$ STD) & PPN (N 2 STD) & PAN (CIMS) & PPN (CIMS) \\
\hline $\mathrm{RF}_{\mathrm{u}}$ & $761 \pm 47$ & nd & $280 \pm 5$ & $272 \pm 8$ & nd & nd \\
$\mathrm{RF}_{\mathrm{cor}}$ & $774 \pm 42$ & nd & $281 \pm 5$ & $277 \pm 10$ & $23.3 \pm 0.5$ & $22.5 \pm 1.0$ \\
$\mathrm{RSD}$ & $5.4 \%$ & nd & $1.7 \%$ & $3.6 \%$ & $2.1 \%$ & $4.4 \%$ \\
$r$ & 0.985 & nd & 0.997 & 0.994 & 0.993 & 0.989 \\
$n$ & 6 & - & 11 & 6 & 16 & 7 \\
Relative response & 1 & nd & 1 & $0.99 \pm 0.04$ & 1 & $0.97 \pm 0.05$ \\
\hline
\end{tabular}

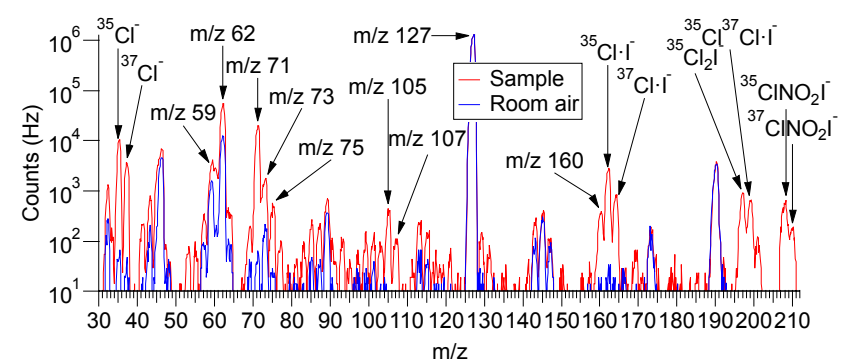

Figure 6. Iodide ion chemical ionization mass spectra of an APAN standard and room air.

The calibration plots were linear $(r>0.96$ in all cases, and often $r>0.99$ ), and allowed precise determination of the response factors that are summarized in Tables 3 and 4. Alternatively, response factors could have been calculated from the daily ratios of GC area against $\Sigma$ PN; however, since this method would only be a single-point calibration, it was judged to be less accurate and reliable than the conventional calibration plot method.

Table 3 summarizes the response factors determined during the Abbotsford campaign. For PAN, the initially used "CAP" setting was more sensitive (by a factor of 2.8) than the $\mathrm{N}_{2}$ STD setting, but was less reproducible ( $5 \%$ relative standard deviation (RSD) vs. $2 \%$ RSD). The lower reproducibility was coincidental and likely caused by greater temperature fluctuations within the trailer during the initial days of the measurements (the PAN-GC was next to a door). Six PPN calibrations were also performed, which showed PPN to have about the same response factors as PAN $(0.99 \pm 0.04)$.

Figure 7 shows the calibration plots for the FOSSILS campaign. The output of the diffusion sources was intentionally allowed to vary between calibration runs (by not keeping the submersion depth of the trap in the ice-water bath constant) during FOSSILS; as a result, the calibration data cover a wide range of mixing ratios (from $\sim 0.2$ to $\sim 10 \mathrm{ppbv}$ ). Tables 4 and 5 summarize the response factors determined during the FOSSILS field campaign. Each response factor was
Table 4. Response factors (in $\mathrm{mV} \mathrm{spbv}^{-1}$ ) of the PAN-GC for PAN, PPN, and MPAN during FOSSILS 2013 with the initial flow settings. Abbreviations are the same as in Table 3.

\begin{tabular}{llll}
\hline Parameter & PAN & PPN & MPAN \\
\hline $\mathrm{RF}_{\mathrm{u}}$ & $633 \pm 13$ & $538 \pm 24$ & $178 \pm 10$ \\
$\mathrm{RF}_{\mathrm{cor}}$ & $636 \pm 11$ & $576 \pm 8$ & $529 \pm 27$ \\
$\mathrm{RSD}$ & $1.7 \%$ & $1.4 \%$ & $5.1 \%$ \\
$r$ & 0.993 & 0.997 & 0.962 \\
$n$ & 29 & 16 & 17 \\
\hline
\end{tabular}

determined with a very low relative standard deviation (RSD, less than $5 \%$, and often less than $2 \%$ ).

At times, substantial corrections (in particular for MPAN) had to be applied to the $\Sigma$ PN data, because the calibration standard contained one or more of the other PANs as an impurity. During the FOSSILS campaign, the purity of the MPAN diffusion standard improved over time (from $~ 73 \%$ PAN content at the beginning of the campaign to $6 \%$ near the end), which suggests that PAN (the major impurity in the MPAN standard) is more volatile than MPAN.

The response factors when the PAN-GC was operated with a slower sample flow rate (Table 5, Fig. 7b) were systematically greater than those when the PAN-GC was operated with a faster sample flow rate (Table 4, Fig. 7a). In addition, the standard widths of the fits were $\sim 20 \%$ larger (Fig. A1 in the Appendix). The differences arise from a change in the absolute number of molecules injected onto the column; while the sample loop volume ( $1.0 \mathrm{~mL}$ internal volume) was the same in both cases, the pressure inside the sample loop was lower at a faster flow rate, because the $1 / 16^{\prime \prime}$ o.d. connecting the tubing acted as a flow restriction.

Table 6 and Fig. A2 in the Appendix summarize PANGC response factors of PAN, PPN and APAN determined in the laboratory following the FOSSILS campaign. The relative response factors of PPN : PAN were $(0.96 \pm 0.04): 1$, slightly higher than during FOSSILS and slightly lower than in Abbotsford. The APAN peak areas correlated linearly with 

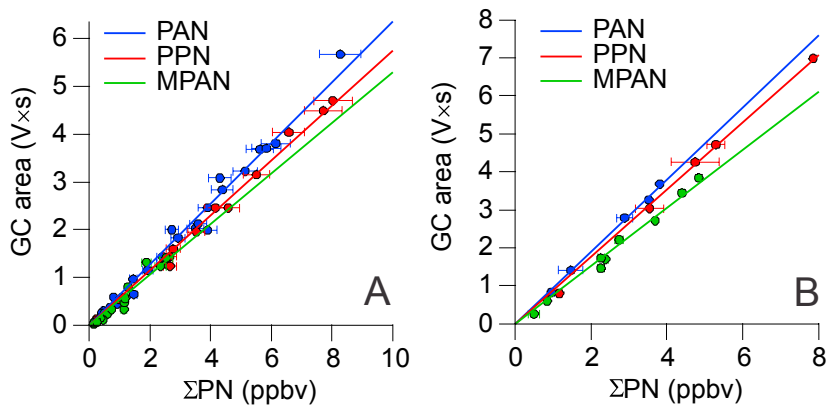

Figure 7. Calibration plots of PAN-GC vs. TD-CRDS during FOSSILS 2013. (a, left) Data collected under the initial sampling conditions. (b, right) Data collected after a change in the sample flow rate due to pump failure. The error bars indicate the precision of the measurements $( \pm 1 \sigma)$ that include the instability of the source output. See Tables 3 and 4 for the linear regression statistics.

Table 5. Response factors (in $\mathrm{mV} \mathrm{sppbv}^{-1}$ ) of the PAN-GC for PAN, PPN, and MPAN during FOSSILS 2013, after the switch to a lower flow rate. Abbreviations are as in Table 3.

\begin{tabular}{llll}
\hline Parameter & PAN & PPN & MPAN \\
\hline $\mathrm{RF}_{\mathrm{u}}$ & $943 \pm 12$ & $877 \pm 13$ & $624 \pm 25$ \\
$\mathrm{RF}_{\mathrm{cor}}$ & $950 \pm 11$ & $886 \pm 12$ & $764 \pm 15$ \\
$\mathrm{RSD}$ & $1.2 \%$ & $1.4 \%$ & $2.0 \%$ \\
$r$ & 0.999 & 0.999 & 0.997 \\
$n$ & 5 & 5 & 9 \\
\hline
\end{tabular}

the $\Sigma$ PN mixing ratios $(r=0.981)$. As shown in Sect. 3.2, the APAN standard contained several PAN-type compounds as impurities; however, only the mixing ratio of PAN could be determined accurately and subtracted from $\Sigma$ PN. The response factor for APAN is hence a lower limit to its true value. The sum of impurity peak counts (other than those of PAN) observed in the CI mass spectrum (Sect. 3.2) is approximately $12 \%$ relative to APAN. Conservatively assuming equal sensitivity of the TD-CIMS to all PANs, the response factor of the PAN-GC for APAN is estimated at 0.85 relative to PAN. If the TD-CIMS sensitivity to the impurities is lower than to PAN (which is likely; see Sect. 3.4), the PAN-GC response factor relative to PAN approaches unity.

\subsection{TD-CIMS response factors}

The output of the diffusion sources was also used to determine the response factors of the TD-CIMS, for PAN and PPN in Abbotsford (Table 3), and for all four PANs in laboratory experiments (Fig. A3 in the Appendix and Table 8). The response factors for PAN, PPN, and MPAN are consistent with those reported earlier by our group with the same instrument (Mielke et al., 2011, 2013; Mielke and Osthoff, 2012) and by Zheng et al. (2011) (Table 9). For MPAN, some variability in the response factor is expected, as the MPA radical
Table 6. Response factors (in $\mathrm{mV} \mathrm{spbv}^{-1}$ ) of the PAN-GC for PAN, PPN, MPAN and APAN, determined after the FOSSILS campaign. Abbreviations are as in Table 3.

\begin{tabular}{lllll}
\hline Parameter & PAN & PPN & MPAN & APAN \\
\hline $\mathrm{RF}_{\mathrm{u}}$ & $662 \pm 24$ & $637 \pm 8$ & nd & $451 \pm 13$ \\
$\mathrm{RF}_{\mathrm{cor}}$ & $662 \pm 24$ & $637 \pm 8$ & nd & $(513 \pm 13)^{*}$ \\
$\mathrm{RSD}$ & $3.6 \%$ & $1.3 \%$ & nd & $2.5 \%$ \\
$r$ & 0.990 & 0.9997 & nd & 0.981 \\
$n$ & 8 & 6 & - & 5 \\
\hline
\end{tabular}

* Corrected for PAN only

dissociates at (and at a rate that varies sharply with) the TD-CIMS inlet temperature. The response factor for APAN, corrected for $\sim 21 \%$ of the total impurities (Sect. 3.2), was greater than $(0.75 \pm 0.02)$, and is likely higher still if the sensitivity of the impurities is less than that of PAN. The range of values is greater in this work than that reported by Zheng et al. (2011), who reported obtaining different response factors depending on the calibration method, interpreted as caused by standard impurities such as acrylic acid.

\subsection{Measurement of PAN and PPN in Abbotsford}

Sample chromatograms of ambient air during the Abbotsford campaign are shown in Figs. 8 and 9. Fitted parameters are summarized in Table 10. These particular chromatograms were chosen because they correspond to the periods with the highest (1.6 ppbv, Fig. 8) and lowest (8 pptv, Fig. 9) PAN mixing ratios. The latter was close to the PAN detection limit ( $\sim 4$ pptv during Abbotsford). In addition to the broad and off-scale $\mathrm{O}_{2}$ peak eluting at $\sim 0.5 \mathrm{~min}$ and the PAN and PPN peaks identified using standard injections, the chromatograms generally contained a large peak that eluted at $\sim 1 \mathrm{~min}$ and another that eluted just after $3 \mathrm{~min}$ (a bit earlier than where APAN would have eluted). The areas of these peaks did not vary as much as those of the PANs, suggesting that the associated compounds are longer lived in the atmosphere than PAN (consistent with, for example, chlorofluorocarbons such as $\mathrm{CCl}_{4}$ ).

When PAN concentrations were high, additional peaks appeared in the chromatograms. In Fig. 8, for example, the retention time of the peak eluting at $318 \mathrm{~s}$ is consistent with PiBN. Larger PANs, including MPAN, eluted after 6 min and appeared as ghost peaks in subsequent chromatograms (see, for example, the peaks around a retention time of $90 \mathrm{~s}$ in Fig. 8). Because their peak areas were small, they did not significantly interfere with the determination of PAN or PPN. However, the appearance of ghost peaks is undesirable, and was eliminated by increasing the time between runs (from 6 to $10 \mathrm{~min}$ ) and by the reducing the column length (from 20.41 to $10.4 \mathrm{~m}$ ) for the FOSSILS campaign (see Sect. 3.6 below). 


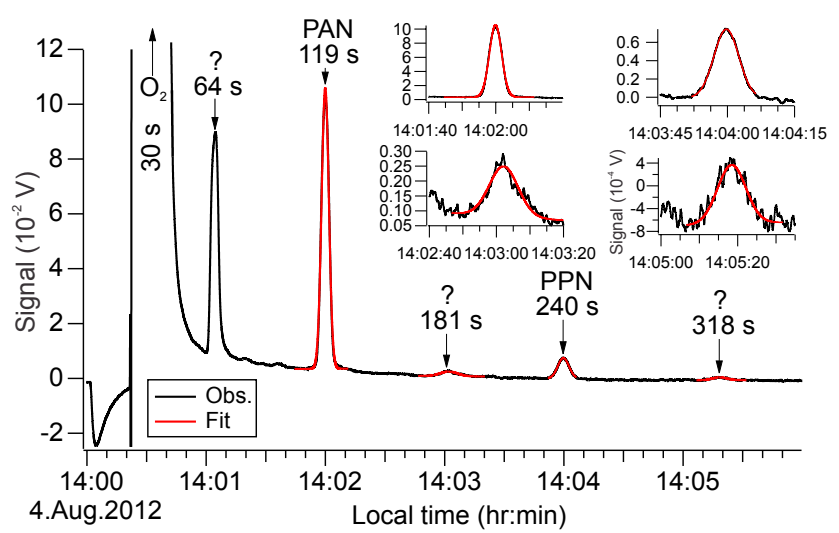

Figure 8. Chromatogram of ambient air acquired in Abbotsford on 4 August 2012, 14:00 local time. The red lines are fits of Eq. (1) to the observed peaks, which are also shown as inserts. The peak areas correspond to a PAN mixing ratio of $1.67 \mathrm{ppbv}$ and a PPN mixing ratio of $163 \mathrm{pptv}$, which were the largest peak areas observed in Abbotsford.

Table 7. Relative response factors of the PAN-GC for PAN, PPN, MPAN and APAN, and recent literature values. nd = not determined; $\mathrm{nr}=$ determined, but not disclosed.

\begin{tabular}{lclll}
\hline Reference & PAN & PPN & MPAN & APAN \\
\hline $\begin{array}{l}\text { Grosjean et } \\
\text { al. (1993b) }\end{array}$ & 1 & $0.73-0.81$ & $\mathrm{nr}$ & $\mathrm{nd}$ \\
\hline $\begin{array}{l}\text { Williams et } \\
\text { al. (1993) }\end{array}$ & 1 & $0.72 \pm 0.15$ & $0.21 \pm 0.04$ & $\mathrm{nd}$ \\
\hline $\begin{array}{l}\text { Williams et } \\
\text { al. (2000) }\end{array}$ & 1 & 0.83 & 0.72 & $\mathrm{nd}$ \\
\hline $\begin{array}{l}\text { Roberts et } \\
\text { l. (2001) }\end{array}$ & 1 & 0.83 & $\mathrm{nr}$ & $(0.92)^{*}$ \\
\hline $\begin{array}{l}\text { Flocke et } \\
\text { al. (2005) }\end{array}$ & 1 & $0.90 \pm 0.02$ & $0.64 \pm 0.03$ & $(0.80 \pm 0.15)^{*}$ \\
\hline $\begin{array}{l}\text { Zheng et } \\
\text { al. (2011) }\end{array}$ & 1 & $\mathrm{nd}$ & $\mathrm{nd}$ & $0.959 \pm 0.006$ \\
\hline $\begin{array}{l}\text { This work } \\
\text { (Abbotsford) }\end{array}$ & 1 & $0.99 \pm 0.04$ & $\mathrm{nd}$ & $\mathrm{nd}$ \\
\hline $\begin{array}{l}\text { This work } \\
\text { (FOSSILS 1) }\end{array}$ & 1 & $0.91 \pm 0.02$ & $0.83 \pm 0.04$ & $\mathrm{nd}$ \\
\hline $\begin{array}{l}\text { This work } \\
\text { (FOSSILS 2) }\end{array}$ & 1 & $0.93 \pm 0.02$ & $0.80 \pm 0.02$ & $\mathrm{nd}$ \\
\hline $\begin{array}{l}\text { This work } \\
\text { (Laboratory) }\end{array}$ & 1 & $0.96 \pm 0.04$ & $\mathrm{nd}$ & $>(0.77 \pm 0.03)^{* *}$ \\
$*$ Estimated; ** corrected for PAN only. & & \\
\hline
\end{tabular}

Figure 10 shows the time series of PAN and PPN (top) and of $\mathrm{O}_{3}, \mathrm{NO}$ and $\mathrm{NO}_{2}$ (bottom) for the Abbotsford data set. PAN and PPN mixing ratios exhibited a strong diurnal profile that paralleled that of $\mathrm{O}_{3}$, with maxima in the late afternoon. The PAN-GC and TD-CIMS data each cover the full dynamic range of the PAN mixing ratios in Abbotsford

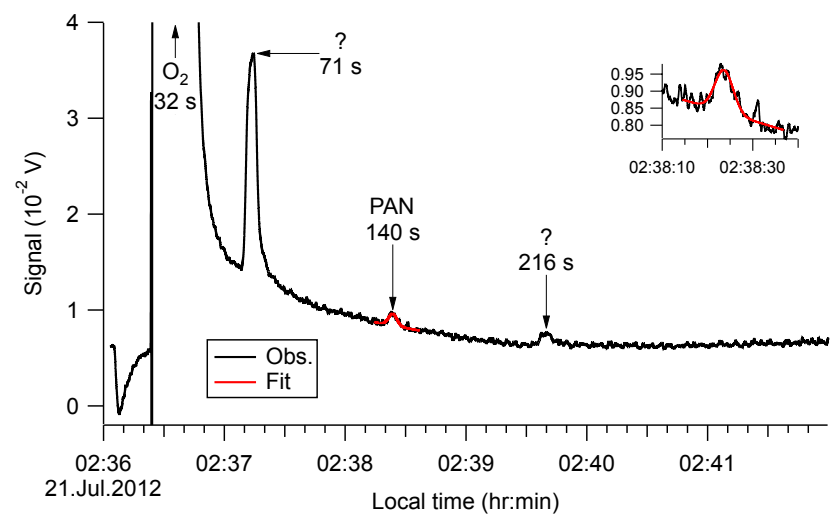

Figure 9. Chromatogram of ambient air acquired in Abbotsford on 21 July 2012, 02:36 local time with the PAN-GC operated in "CAP" setting mode. Other conditions were the same as in Fig. 8. The peak area corresponds to a PAN mixing ratio of $(8.1 \pm 0.4)$ pptv. Retention times are greater than in Fig. 8 due to a lower column temperature.

Table 8. Response factors of the TD-CIMS for PAN, PPN, MPAN and APAN determined in the laboratory. Uncorrected response factors $\left(\mathrm{RF}_{\mathrm{u}}\right)$, response factors corrected for sample impurities, when quantifiable $\left(\mathrm{RF}_{\mathrm{cor}}\right)$, zero offsets $(b)$, the $r$ value of the calibration plot, and response factors relative to PAN. TD-CIMS counts were normalized to $1 \times 10^{6}$ reagent ion counts at $m / z 127$.

\begin{tabular}{lllll}
\hline $\begin{array}{l}\text { Parameter } \\
\text { (unit) }\end{array}$ & PAN & PPN & MPAN & APAN \\
\hline $\begin{array}{l}\mathrm{RF}_{\mathrm{u}} \\
\left(\mathrm{Hz} \mathrm{pptv}^{-1}\right)\end{array}$ & $27.7 \pm 0.3$ & $24.7 \pm 0.3$ & $0.64 \pm 0.02$ & $16.5 \pm 0.4$ \\
$\mathrm{RF}_{\mathrm{cor}}$ & $27.7 \pm 0.3$ & $25.1 \pm 0.3$ & $0.8 \pm 0.1$ & $>20.9 \pm 0.4$ \\
$\left(\mathrm{~Hz} \mathrm{pptv}^{-1}\right)$ & & & & \\
$\mathrm{RSD}$ & $1.1 \%$ & $1.2 \%$ & $12.5 \%$ & $1.9 \%$ \\
$b\left(10^{3} \mathrm{~Hz}\right)$ & $1.8 \pm 0.6$ & $3.1 \pm 0.3$ & $0.27 \pm 0.05$ & $2.0 \pm 0.5$ \\
$r$ & 0.99 & 0.98 & 0.97 & 0.99 \\
\hline
\end{tabular}

* Corrected for PAN-like impurities (see text).

(from $\sim 8$ to $1.6 \mathrm{ppbv}$ ). For PPN, on the other hand, the lowest quantified mixing ratio from the PAN-GC was 16 pptv; hence, GC data are only available on days with relatively large PPN concentrations. In contrast, the TD-CIMS was able to monitor PPN down to single pptv mixing ratios, and quantification of PPN by the PAN-GC was limited by the ability to fit the chromatographic peaks; for most of the Abbotsford data set, the PPN peak areas were too small to fit.

Figure 11 shows scatter plots of PAN-GC against TDCIMS ambient air data. For PAN, the agreement between the PAN-GC and the raw TD-CIMS data is reasonable $(r=0.94$, slope $=0.84 \pm 0.01$, Fig. 11a), and improves after the correction for TD-CIMS matrix effects arising from titration by NO and $\mathrm{NO}_{2}$ is applied $(r=0.93$, slope $=0.96 \pm 0.01$, Fig. 11c). For PPN, the uncorrected TD-CIMS data do not correlate well with PAN-GC data $(r=0.54$, slope $=0.54 \pm 0.05$, Fig. 11b), but more so after the correction for inlet matrix effects is applied $(r=0.77$, slope $=1.03 \pm 0.07$, Fig. 11d). 
Table 9. Relative response factors of the TD-CIMS for PAN, PPN, MPAN and APAN in this work and recent literature values. "nd" means not determined or reported.

\begin{tabular}{|c|c|c|c|c|}
\hline Reference & PAN & PPN & MPAN & APAN \\
\hline Slusher et al. (2004) & 1 & 1 & 0.16 & nd \\
\hline Turnipseed et al. (2006) & 1 & 1 & 0.125 & nd \\
\hline Wolfe et al. (2007) & 1 & 1 & 0.125 & 1 \\
\hline $\begin{array}{l}\text { LaFranchi et al. (2009); } \\
\text { Wolfe et al. (2009) }\end{array}$ & 1 & 1 & 0.232 & nd \\
\hline Zheng et al. (2011) & 1 & $1.13 \pm 0.16$ & $0.014 \pm 0.002$ & $\begin{array}{l}0.66 \pm 0.10 \text { (cal source) } \\
0.37 \text { (FTIR in chamber) } \\
0.35 \pm 0.04 \text { (recommended) }\end{array}$ \\
\hline Mielke and Osthoff (2012) & 1 & 1 & 0.022 & nd \\
\hline This work & 1 & $0.91 \pm 0.01$ & $0.029 \pm 0.004$ & $>(0.75 \pm 0.02)^{*}$ \\
\hline
\end{tabular}

* Corrected for PAN only.

Table 10. Parameters of Eq. (1) fitted to the chromatograms in Figs. 8 and 9.

\begin{tabular}{|c|c|c|c|}
\hline Parameter (unit) & PAN (Fig. 8) & PAN (Fig. 9) & PPN (Fig. 8) \\
\hline$t_{0}(\mathrm{~s})$ & $119.894 \pm 0.001$ & $140.00 \pm 0.01$ & $239.76 \pm 0.001$ \\
\hline$\sigma(\mathrm{s})$ & $1.824 \pm 0.001$ & $2.03 \pm 0.01$ & $2.810 \pm 0.001$ \\
\hline$V_{0}(\mathrm{mV})$ & $1.66 \pm 0.02$ & $13.97 \pm 0.07$ & $3.15 \pm 0.03$ \\
\hline$m\left(\mathrm{~V} \mathrm{~s}^{-1}\right)$ & $-(1.5 \pm 0.2) \times 10^{-5}$ & $-(3.99 \pm 0.05) \times 10^{-5}$ & $-(5.48 \pm 0.04) \times 10^{-5}$ \\
\hline$A(\mathrm{mV} \mathrm{s})$ & $468.02 \pm 0.25$ & $6.26 \pm 0.05$ & $45.24 \pm 0.03$ \\
\hline $\mathrm{RF}_{\text {cor }}\left(\mathrm{mV} \mathrm{s} \mathrm{ppbv}{ }^{-1}\right)$ & $281 \pm 5$ & $774 \pm 42$ & $277 \pm 10$ \\
\hline Mixing ratio (pptv) & $1670 \pm 30$ & $8.1 \pm 0.4$ & $163 \pm 6$ \\
\hline
\end{tabular}

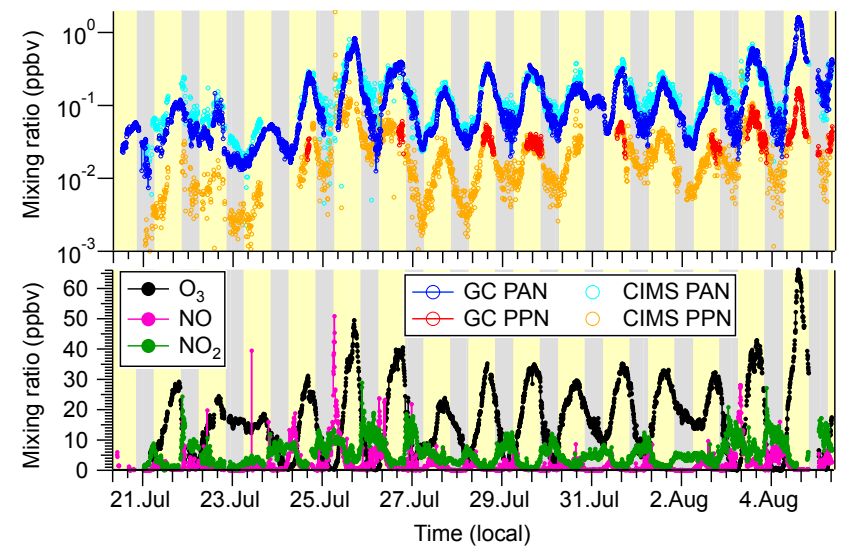

Figure 10. Time series of PAN and PPN (top) and the $\mathrm{NO}, \mathrm{NO}_{2}$, and $\mathrm{O}_{3}$ mixing ratios (bottom) observed in Abbotsford.

\subsection{Measurement of PAN, PPN, and MPAN during FOSSILS}

Figure 12 shows a typical chromatogram of ambient air and of a blank (i.e., when the PAN-GC sampled zero air) acquired during FOSSILS. Fitted parameters are summarized in Table 11. The blank chromatogram demonstrates the absence of ghost peaks. The ambient air chromatogram shows peaks associated with PAN (121 pptv), PPN (13 pptv), and MPAN (10 pptv). The approximate elution time of APAN is noted, but its area was too small to be fitted. The retention times of peaks labeled with question marks do not correspond to any of the known PANs; they are likely either alkyl nitrates or halogenated compounds.

Figure 13 shows the time series of the PAN, PPN, and MPAN mixing ratios observed during FOSSILS. In total, 3635 chromatograms were analyzed, with 3354 (2449, 2061) containing PAN (PPN, MPAN) at concentration levels above their respective detection limits (see below). The mixing ratios varied with the time of day, generally peaked in the mid-afternoon, and were highly correlated with each other, as expected. On average, the ratios of PPN / PAN and MPAN / PAN were $\sim 1: 10$, and varied from $\sim 1: 5$ to $\sim 1: 20$. An analysis of these ratios to gain insights into the relative contributions of biogenic and anthropogenic hydrocarbons during the photochemical production of $\mathrm{O}_{3}$ (e.g., Roberts et al., 1998, 2002, 2007) will be presented elsewhere. 
Table 11. Parameters of Eq. (1) fitted to the chromatogram in Fig. 12.

\begin{tabular}{llll}
\hline Parameter (unit) & PAN & PPN & MPAN \\
\hline$t_{0}(\mathrm{~s})$ & $113.575 \pm 0.005$ & $245.12 \pm 0.02$ & $406.21 \pm 0.03$ \\
$\sigma(\mathrm{s})$ & $2.083 \pm 0.006$ & $3.87 \pm 0.02$ & $5.060 \pm 0.035$ \\
$V_{0}(\mathrm{mV})$ & $131.66 \pm 0.15$ & $128.54 \pm 0.03$ & $127.28 \pm 0.02$ \\
$m\left(\mathrm{~V} \mathrm{~s}^{-1}\right)$ & $-(3.19 \pm 0.34) \times 10^{-5}$ & $(1.81 \pm 0.29) \times 10^{-6}$ & $(7.73 \pm 0.13) \times 10^{-6}$ \\
$A\left(\mathrm{mV} \mathrm{s}^{-6}\right.$ & $115.4 \pm 0.3$ & $12.04 \pm 0.06$ & $7.80 \pm 0.06$ \\
$\mathrm{RF}_{\text {cor }}\left(\mathrm{mV} \mathrm{sppbv}{ }^{-1}\right)$ & $950 \pm 11$ & $886 \pm 12$ & $764 \pm 15$ \\
Mixing ratio (pptv) & $121.5 \pm 1.5$ & $13.6 \pm 0.2$ & $10.2 \pm 0.3$ \\
\hline
\end{tabular}

Table 12. Parameters of Eq. (1) fitted to a selection of PAN peaks in the chromatograms acquired during the night of 2 to 3 September 2013. Data for the peaks shown in Fig. 14 are highlighted in bold font. The errors are those reported by the IGOR software, except for the PAN mixing ratio, which was calculated by adding errors in the calibration uncertainty and the error in the peak area (reported by IGOR) in quadrature. Note that the fit of the peak in the 8:10 chromatogram did not converge.

\begin{tabular}{|c|c|c|c|c|c|c|}
\hline $\begin{array}{l}\text { Time of } \\
\text { injection (UTC) }\end{array}$ & $t_{0}(\mathrm{~s})$ & $\sigma(\mathrm{s})$ & $V_{0}(\mathrm{mV})$ & $m\left(10^{-6} \mathrm{~V} \mathrm{~s}^{-1}\right)$ & $A(\mathrm{mV} \mathrm{s})$ & PAN (pptv) \\
\hline 06:00 & $110.13 \pm 0.02$ & $2.07 \pm 0.02$ & $0.12106 \pm 0.00005$ & $-22.5 \pm 0.4$ & $12.1 \pm 0.1$ & $12.7 \pm 0.2$ \\
\hline 06:10 & $110.41 \pm 0.02$ & $2.07 \pm \mathbf{0 . 0 2}$ & $0.12098 \pm 0.00005$ & $-25.4 \pm 0.4$ & $11.4 \pm 0.1$ & $12.0 \pm 0.2$ \\
\hline $06: 20$ & $110.53 \pm 0.02$ & $2.08 \pm 0.02$ & $0.12014 \pm 0.00004$ & $-23.5 \pm 0.4$ & $11.8 \pm 0.1$ & $12.4 \pm 0.2$ \\
\hline $06: 30$ & $110.60 \pm 0.02$ & $2.09 \pm 0.03$ & $0.11873 \pm 0.00005$ & $-16.9 \pm 0.4$ & $8.9 \pm 0.1$ & $9.3 \pm 0.2$ \\
\hline $06: 40$ & $109.98 \pm 0.02$ & $2.08 \pm 0.02$ & $0.11866 \pm 0.00005$ & $-20.5 \pm 0.4$ & $8.9 \pm 0.1$ & $9.3 \pm 0.1$ \\
\hline $06: 50$ & $110.07 \pm 0.03$ & $2.09 \pm 0.03$ & $0.11849 \pm 0.00004$ & $-23.4 \pm 0.4$ & $6.2 \pm 0.1$ & $6.5 \pm 0.1$ \\
\hline 07:00 & $109.72 \pm 0.03$ & $2.08 \pm 0.03$ & $0.11771 \pm 0.00005$ & $-20.6 \pm 0.5$ & $7.3 \pm 0.1$ & $7.7 \pm 0.1$ \\
\hline 07:10 & $108.41 \pm 0.09$ & $2.09 \pm 0.09$ & $0.11769 \pm 0.00004$ & $-23.6 \pm 0.4$ & $2.4 \pm 0.1$ & $2.6 \pm 0.1$ \\
\hline 07:20 & $109.89 \pm 0.02$ & $2.08 \pm 0.02$ & $0.11770 \pm 0.00005$ & $-25.8 \pm 0.4$ & $9.1 \pm 0.1$ & $9.6 \pm 0.2$ \\
\hline 07:30 & $108.96 \pm 0.07$ & $2.09 \pm 0.07$ & $0.11693 \pm 0.00004$ & $-22.4 \pm 0.3$ & $2.6 \pm 0.1$ & $2.8 \pm 0.1$ \\
\hline 07:40 & $108.35 \pm 0.04$ & $2.08 \pm 0.05$ & $0.11656 \pm 0.00004$ & $-22.0 \pm 0.4$ & $3.6 \pm 0.1$ & $3.8 \pm 0.1$ \\
\hline 07:50 & $108.55 \pm 0.08$ & $2.08^{*}$ & $0.11648 \pm 0.00005$ & $-24.2 \pm 0.4$ & $2.7 \pm 0.1$ & $2.8 \pm 0.1$ \\
\hline 08:00 & $108.80 \pm 0.08$ & $2.08^{*}$ & $0.11600 \pm 0.00004$ & $-23.2 \pm 0.4$ & $2.7 \pm 0.1$ & $2.8 \pm 0.1$ \\
\hline 08:10 & - & - & - & - & - & - \\
\hline 08:20 & $109.22 \pm 0.07$ & $2.09 \pm 0.07$ & $0.11578 \pm 0.00004$ & $-23.0 \pm 0.4$ & $2.8 \pm 0.1$ & $2.9 \pm 0.1$ \\
\hline $08: 30$ & $108.21 \pm 0.06$ & $2.09^{*}$ & $0.11578 \pm 0.00004$ & $-24.4 \pm 0.4$ & $2.0 \pm 0.1$ & $2.1 \pm 0.1$ \\
\hline 08:40 & $107.17 \pm 0.17$ & $2.09^{*}$ & $0.11559 \pm 0.00004$ & $-24.2 \pm 0.4$ & $1.5 \pm 0.1$ & $1.6 \pm 0.2$ \\
\hline $08: 50$ & $108.20 \pm 0.10$ & $2.08 \pm 0.10$ & $0.11538 \pm 0.00004$ & $-24.3 \pm 0.4$ & $1.6 \pm 0.1$ & $1.7 \pm 0.1$ \\
\hline 09:00 & $106.70 \pm 0.10$ & $2.08^{*}$ & $0.11536 \pm 0.00003$ & $-26.3 \pm 0.3$ & $1.7 \pm 0.1$ & $1.8 \pm 0.1$ \\
\hline 09:10 & $107.68 \pm 0.07$ & $2.08^{*}$ & $0.11535 \pm 0.00005$ & $-27.3 \pm 0.4$ & $1.6 \pm 0.1$ & $1.7 \pm 0.1$ \\
\hline 09:20 & $106.80 \pm 0.15$ & $2.09 \pm 0.16$ & $0.11447 \pm 0.00004$ & $-21.3 \pm 0.3$ & $1.1 \pm 0.1$ & $1.1 \pm 0.1$ \\
\hline 09:30 & $106.59 \pm 0.13$ & $2.08 \pm 0.14$ & $0.11453 \pm 0.00004$ & $-22.0 \pm 0.4$ & $1.1 \pm 0.1$ & $1.1 \pm 0.1$ \\
\hline 09:40 & $106.90 \pm 0.11$ & $2.07 \pm 0.12$ & $0.11451 \pm 0.00004$ & $-23.3 \pm 0.4$ & $1.5 \pm 0.1$ & $1.6 \pm 0.1$ \\
\hline 09:50 & $106.46 \pm 0.17$ & $2.07^{*}$ & $0.11429 \pm 0.00004$ & $-21.8 \pm 0.4$ & $1.5 \pm 0.1$ & $1.6 \pm 0.1$ \\
\hline 10:00 & $104.45 \pm 0.17$ & $2.07^{*}$ & $0.11429 \pm 0.00004$ & $-22.6 \pm 0.4$ & $1.6 \pm 0.1$ & $1.6 \pm 0.1$ \\
\hline $10: 10$ & $106.90 \pm 0.11$ & $2.06 \pm 0.12$ & $0.11439 \pm 0.00005$ & $-24.5 \pm 0.5$ & $1.8 \pm 0.1$ & $1.9 \pm 0.1$ \\
\hline $10: 20$ & $107.30 \pm 0.09$ & $2.07 \pm 0.09$ & $0.11429 \pm 0.00004$ & $-24.3 \pm 0.4$ & $1.9 \pm 0.1$ & $2.0 \pm 0.1$ \\
\hline
\end{tabular}

$* \sigma$ constrained to the value from the preceding run.

At night, the PAN concentrations frequently dropped below quantifiable limits, because the relatively warm nocturnal temperatures facilitated thermal decomposition of PANs and because the high nocturnal NO concentrations from nearby anthropogenic activities titrated the peroxyacyl radicals. Data from such nights provided good opportunities to probe the PAN-GC detection limits. Table 12 summarizes fits of the PAN peak during the night of 3 September, which is an example of when PAN dropped near (and eventually below) quantifiable levels. Example fits are shown in Fig. 14. Analogous case studies for PPN and MPAN are shown in Figs. A4 and A5 in the Appendix. The peaks in Fig. 14a and b are well above the limit of detection and quantification (even if the unsmoothed data had been used), and could have been fitted without any prior knowledge of the elution time and shape of the peak. In contrast, the fit of the peak shown in 
A
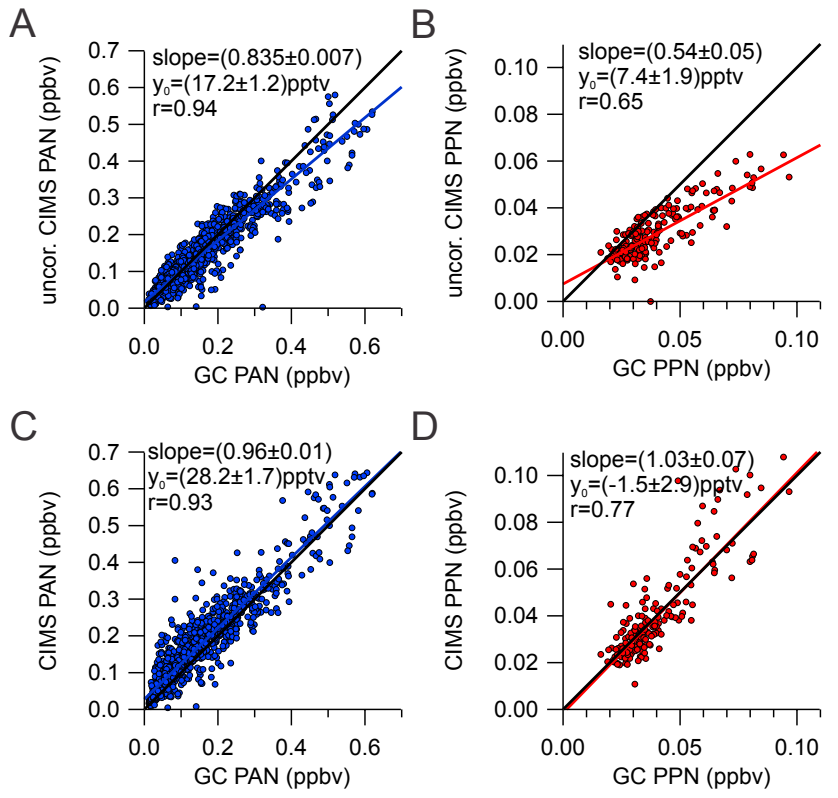

Figure 11. Scatter plots of TD-CIMS and PAN-GC data. (a) PAN, uncorrected. (b) PPN, uncorrected. (c) PAN, corrected. (d) PPN, corrected.

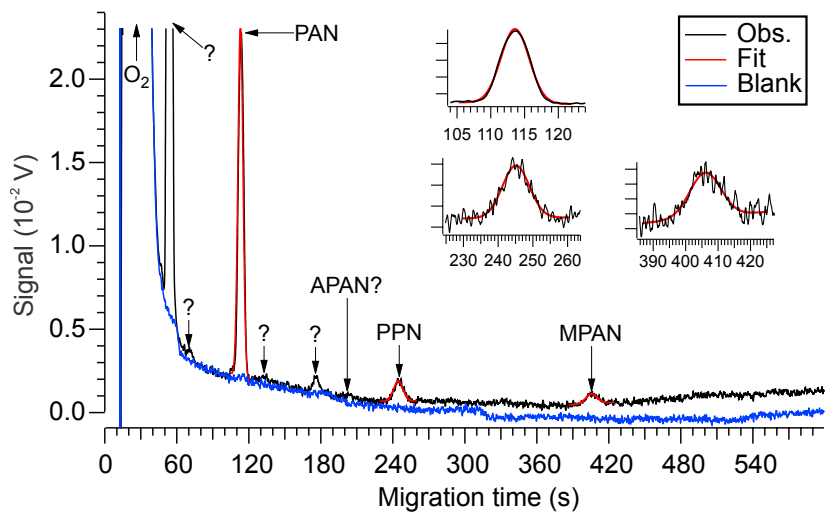

Figure 12. Chromatogram of ambient air acquired during FOSSILS on 4 September 2013, 15:30 local time, and of the zero air blank acquired at 17:30 local time using a 10.4 m RTX-1701 column at a He flow rate of $20.0 \mathrm{~mL} \mathrm{~min}^{-1}$. The chromatograms were smoothed before presentation (algorithm: Savitzky-Golay, fourth order, 41 data points, $\sim 2 \mathrm{~s}$ ). The red lines are fits of Eq. (1) to the observed peaks, which are superimposed as inserts for clarity. The peak areas correspond to the following mixing ratios: PAN: $(121.5 \pm 1.5) \mathrm{pptv}$, PPN: $(13.6 \pm 0.2)$ pptv, and MPAN: $(10.2 \pm 0.3)$ pptv.

Fig. $14 \mathrm{c}$ is less certain, as the peak is barely above the background noise. In many cases, the fits converged only because the initial guess was set to the fit results of the preceding run (Table 12). On the basis of data as shown in Figs. 14 and A4 and A5 in the Appendix, the PAN-GC's limits of detection for PAN, PPN, and MPAN during FOSSILS were estimated at 1,2 , and 3 pptv, respectively.

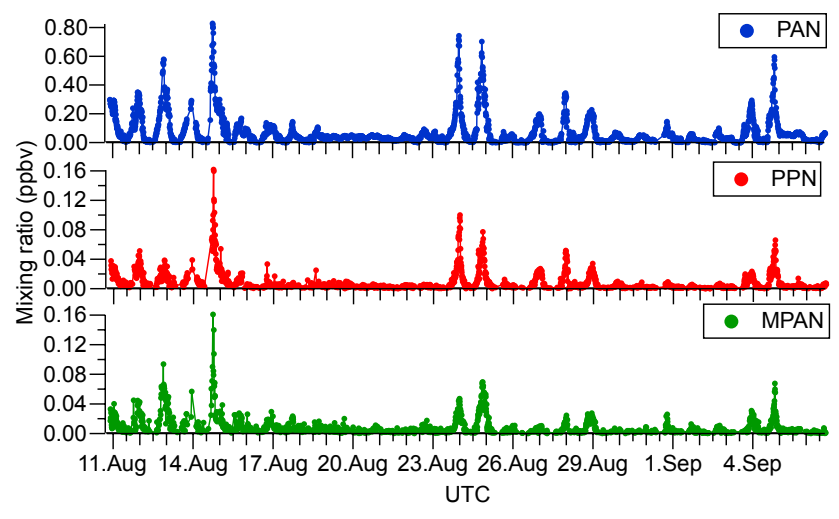

Figure 13. Time series of PAN, PPN, and MPAN during FOSSILS

The (slope) accuracy of the FOSSILS data is limited by the accuracy of the calibration, as the peak fitting procedure produces a (comparatively) small and hence negligible error. For PAN and PPN in particular, the limiting factor was the accuracy of the TD-CRDS, which is $\pm 4 \%$ (Paul and Osthoff, 2010). The accuracy of the MPAN and APAN data is conservatively estimated at \pm 15 and $\pm 25 \%$, respectively, because of the large uncertainties in calibration standard composition.

\section{Discussion}

\subsection{Suitability of TD-CRDS for determining PAN-GC calibration factors}

\subsubsection{PAN and PPN}

The linear correlation of PAN-GC peak areas with TDCRDS $\Sigma$ PN mixing ratios over a wide concentration range (e.g., Fig. 7) affirms that TD-CRDS can be used as a straightforward and easily implemented PAN-GC calibration method for PAN and PPN. The response factors obtained were reproducible over a period approaching one month, which shows that both the TD-CRDS and PAN-GC responses remained stable over that time period.

Small differences in the relative response factors obtained for PAN and PPN were observed between the Abbotsford, FOSSILS, and post-FOSSILS laboratory work (Tables 3-5). This is to be expected, because several parameters, for example the column oven temperature, sample flow rate, and analytical column length, differed between the campaigns. By and large, the results are consistent with each other and with those reported by other groups in the literature (Table 7). For instance, the relative sensitivities of PPN to PAN during FOSSILS were $(0.91 \pm 0.02): 1$ and agreed with the ratio of $0.90 \pm 0.02$ reported by Flocke et al. (2005); postFOSSILS, the relative response factors of PPN : PAN were $(0.96 \pm 0.04): 1$, slightly higher than during FOSSILS and slightly lower than in Abbotsford, but still in agreement with Flocke et al. (2005). 


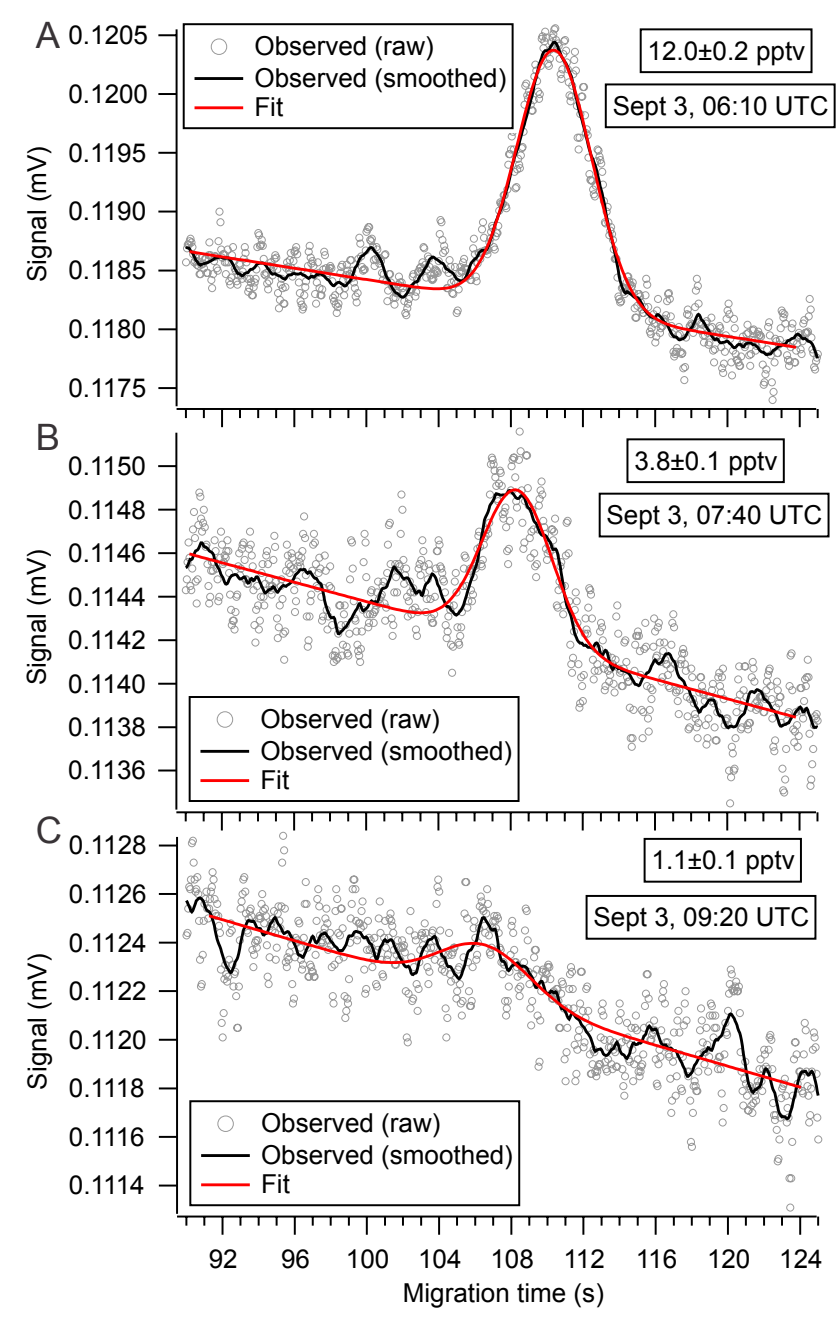

Figure 14. Chromatograms of PAN acquired on 3 September 2013. The fits to the peaks in (a) and (b) were unconstrained; the fit to the peak in (c) was constrained in its width parameter $(\sigma)$ to the earlier determined value (at a higher PAN concentration) of $2.1 \mathrm{~s}$. The mixing ratios are those of the peak area of the fitted line (shown in red).

Alkyl nitrates were also observed in the standard chromatograms. These molecules are formed as byproducts during the synthesis, and are also decomposition products in aged standards. Because TD-CRDS can differentiate between $\Sigma$ PN and $\Sigma$ AN, the presence of alkyl nitrates in the standards could be tolerated, but would have constituted a significant interference if $\mathrm{NO}_{\mathrm{y}} \mathrm{CL}$ (without a preparatoryscale GC) had been used in the calibration. Likewise, $\mathrm{NO}_{2}$, which may be present as a result of thermal decomposition of the PAN standard, is automatically quantified in the ambient temperature reference channel and subtracted (Paul et al., 2009; Paul and Osthoff, 2010).

\subsubsection{MPAN}

The challenges in calibrating a PAN-GC for MPAN (or APAN) are well documented in the literature (e.g., Flocke et al., 2005; Zheng et al., 2011; Roberts et al., 2001), and are associated mainly with the difficult delivery of a highpurity gaseous sample. The use of the TD-CRDS calibration method has the inherent advantage that the $250{ }^{\circ} \mathrm{C}$ channel is insensitive to many of the impurities generated during the MPAN (or APAN) synthesis, i.e., alkyl nitrates, nitryl chloride, and nitric acid (Paul et al., 2009; Paul and Osthoff, 2010). Thus, the TD-CRDS calibration method only requires quantification of (and correction for) PAN impurities.

To determine the response factor for MPAN, the $\Sigma$ PN data had to be corrected for PAN and PPN, which were quantified using the APAN standard chromatogram directly (and their response factors determined earlier). This process was somewhat laborious, but otherwise straightforward. The presence of PAN in synthetic MPAN standards that was observed in all MPAN standards analyzed in this work has been observed before by several groups (Grosjean et al., 1993a; Flocke et al., 2005; Bertman and Roberts, 1991). Flocke et al. (2005) suggested that PAN is produced during the synthesis from impurities in the reagents (i.e., acetic anhydride). While it is possible that PPN is produced in a similar fashion during the synthesis (i.e., from propanoic anhydride that would be present as a trace impurity), PPN originated mostly from memory effects within the Teflon tubing in this work.

Having corrected the MPAN data for PAN and PPN, the MPAN response factor (relative to PAN) was determined at $(0.83 \pm 0.04): 1$ and $(0.80 \pm 0.02): 1$ (Tables $4-5)$. These values are $\sim 25 \%$ greater than the ratio of $(0.64 \pm 0.03): 1$ reported by Flocke et al. (2005), and somewhat greater than the $0.72: 1$ ratio reported by Williams et al. (2000). The reason for the discrepancy between their and our response factor is not clear. It is unlikely that a systematic error from the subtraction of PAN (or PPN) biased the results high, since the response factor for MPAN stayed within a narrow range throughout the FOSSILS campaign, even though the PAN content in the MPAN standard varied from $73 \%$ at the beginning to $6 \%$ at the end of the campaign (concentrations of PPN were generally too small to affect the slope of the calibration plots). It is therefore likely that there are real differences in the sensitivity between the instruments, e.g., due to differences in on-column decomposition rates (Roumelis and Glavas, 1989) between the RTX-200 column used by the other groups and the RTX-1701 column used in this work.

Overall, we conclude on the basis of the linear correlation of $\Sigma$ PN mixing ratios with PAN-GC peak areas that TD-CRDS can be used to calibrate a PAN-GC for MPAN, as was demonstrated in this work, alas with a much greater uncertainty $( \pm 15 \%)$ than the TD-CRDS would allow for in principle $( \pm 4 \%)$. In the future, we intend to construct a preparatory-scale GC similar to the one developed at NOAA 
and NCAR (Williams et al., 2000) to clean up the MPAN output used in the calibration to reduce the uncertainty in the calibration and to eliminate the need to subtract PAN impurities from the $\Sigma$ PN mixing ratio.

\subsubsection{APAN}

For APAN, only a lower limit to the PAN-GC response factor could be determined in this work, because the $\Sigma$ PN measurement was compromised by unusual PAN-like compounds co-emitted by the diffusion source (Fig. 6), many of which (e.g., the chlorinated adduct) could have formed during the synthesis. Their presence is corroborated by multiple impurity peaks observed in the APAN standard chromatogram (Fig. 5a). However, in TD-CIMS, counts at certain masses can be positively biased by proton exchange reactions of carboxylate product ions with acid impurities, and these signals can masquerade as PANs (Mielke and Osthoff, 2012), such that the impurities in Fig. 6 cannot be quantified with any certainty. If these impurities are taken into account, the response factor relative to PAN is estimated to be between 0.85 and 1. This range brackets the response factor of $0.959 \pm 0.006$ reported by Zheng et al. (2011) for their PAN-GC. This consistency and the high linearity of the calibration plots suggest that TD-CRDS can, in principle, be used for accurate APAN calibrations (even though it was not demonstrated in this work). The use of the aforementioned preparatory GC in future experiments will hopefully confirm this.

APAN was synthesized from its acyl chloride in this study. Apparently, $\mathrm{ClNO}_{2}$ is formed during the synthesis from reaction between the chloride anion $\left(\mathrm{Cl}^{-}\right)$liberated from acryloyl chloride and the concentrated sulfuric/nitric acid mixture that generates the nitronium cation $\mathrm{NO}_{2}^{+}$(Behnke et al., 1997), and $\mathrm{ClNO}_{2}$ is sufficiently nonpolar to be extracted from the aqueous solution into tridecane during the workup. Evaporation of $\mathrm{ClNO}_{2}$ from a standard would interfere with a calibration based on $\mathrm{NO}_{\mathrm{y}}$ chemiluminescence, but does not in a TDCRDS $\Sigma$ PN measurement (Thaler et al., 2011). Furthermore, $\mathrm{ClNO}_{2}$ autoionizes to $\mathrm{Cl}^{-}$and $\mathrm{NO}_{2}^{+}$(Behnke et al., 1997), which can add across $\mathrm{C}-\mathrm{C}$ double bonds and, for example, accelerate the degradation of APAN in the standard solution. The presence of $\mathrm{ClNO}_{2}$ in PAN standards is undesirable, and may potentially explain the difficulties documented by, for example, Zheng et al. (2011), and encountered in this work with the determination of APAN response factors. We conclude that PAN syntheses that use acyl chlorides as a starting material should therefore be avoided. The MPAN standard used by Flocke et al. (2005) and Zheng et al. (2011) was synthesized from methacryloyl chloride, and likely also contained $\mathrm{ClNO}_{2}$; it is unclear, however, if (and when) $\mathrm{ClNO}_{2}$ would elute from their preparatory GC column, and if the results were affected by this impurity.

\subsection{Performance of the PAN-GC in the field}

\subsubsection{Chromatography}

The majority of PAN-GC in use today utilizes an RTX200 analytical column (or similar). Tanimoto and coworkers (Tanimoto et al., 1999; Tanimoto and Akimoto, 2001) and Flocke et al. (2005) have described PAN instruments with RTX-1701 columns. While the absence of co-eluting peaks was demonstrated for RTX-200 columns (Williams et al., 2000), no explicit mention has been made so far in the literature confirming the absence of co-eluting peaks (which would positively interfere) for RTX-1701 columns. The agreement between PAN-GC and TD-CIMS data corroborates the (assumed) absence of significant interferences. Nevertheless, a PAN inlet scrubber as shown by Williams et al. (2000) will be implemented for future deployments as a precaution.

There are many PAN-GCs that are equipped with guard columns (e.g., Pätz et al., 2002; Flocke et al., 2005). The absence of any degradation of performance suggests guard columns are not needed, unless one were perhaps to sample in an extraordinarily polluted environment.

The sample chromatograms (Figs. 5, 8, 9, and 12) show that PANs are sufficiently resolved such that a $\sim 50 \%$ shorter column could have been used to speed up the analysis and increase the peak height (and hence improve time resolution and lower the detection limit). A shorter column will be deployed in future studies.

\subsubsection{Limits of detection and accuracy of measurements}

The limits of detection of the University of Calgary PAN-GC are in the single-digit pptv range and of a similar magnitude as, or marginally better than, those reported for other PANGC instruments that have recently been operated in the field (e.g., Thornberry et al., 2001; Roberts et al., 2002, 2006; Table 13). Unfortunately, there is no consensus in the literature on how best to determine limits of detection (LODs) in gas chromatography, and methods such as signal-to-noise, blank determination, and linear regression methods often give different results (e.g., Sanagi et al., 2009). In this work, the LODs were estimated from the smallest peak area that could be fitted (Figs. 14 and A4 and A5 in the Appendix), which is a somewhat subjective evaluation. A more rigorous determination would have required repeated measurements near the LOD; however, for this procedure to succeed, one would have to assume that the output of a low-concentration standard is sufficiently stable to not add to the measurement noise, which is difficult to demonstrate.

The accuracy of the FOSSILS data is limited by the accuracy of the calibration, as the fitting procedure produces a (relatively) negligible error. For PAN and PPN, the limiting factor is the accuracy of the TD-CRDS, which is $\pm 4 \%$ (Paul and Osthoff, 2010), so that the accuracy of the PAN 
Table 13. Selected LODs of ambient air measurements of PAN, PPN and MPAN by GC-ECD reported in the literature. $\mathrm{nr}=$ not reported, nd $=$ not determined.

\begin{tabular}{|c|c|c|c|c|}
\hline Reference & $\begin{array}{l}\text { Measurement } \\
\text { location }\end{array}$ & PAN & PPN & MPAN \\
\hline $\begin{array}{l}\text { Grosjean et } \\
\text { al. (1993b) }\end{array}$ & $\begin{array}{l}\text { California } \\
\text { mountains }\end{array}$ & 10 & 20 & 200 \\
\hline $\begin{array}{l}\text { Williams et } \\
\text { al. (1993) }\end{array}$ & $\begin{array}{l}\text { Atlanta, } \\
\text { Georgia }\end{array}$ & 30 & $\mathrm{nr}$ & $100-150$ \\
\hline $\begin{array}{l}\text { Nouaime et } \\
\text { al. (1998) }\end{array}$ & Tennessee & \multicolumn{3}{|c|}{$2-5$} \\
\hline $\begin{array}{l}\text { Williams et } \\
\text { al. (2000) }\end{array}$ & Tennessee & \multicolumn{3}{|c|}{$<1-5$} \\
\hline $\begin{array}{l}\text { Thornberry et } \\
\text { al. (2001) }\end{array}$ & Michigan & 2 & 3 & 5 \\
\hline $\begin{array}{l}\text { Roberts et } \\
\text { al. (2002) }\end{array}$ & Tennessee & 5 & 5 & 5 \\
\hline $\begin{array}{l}\text { Roberts et } \\
\text { al. (2006) }\end{array}$ & New England & 4 & 4 & 4 \\
\hline This work & $\begin{array}{l}\text { Abbotsford, } \\
\text { British } \\
\text { Columbia }\end{array}$ & 4 & 16 & nd \\
\hline This work & $\begin{array}{l}\text { Fort McKay, } \\
\text { Alberta }\end{array}$ & 1 & 2 & 3 \\
\hline
\end{tabular}

and PPN data is $\pm 4 \% \pm 1$ pptv. For MPAN and APAN, the accuracy is conservatively estimated at $\pm 15 \% \pm 2$ pptv and $\pm 25 \% \pm 3$ pptv, driven mainly by the large uncertainties of calibration standard composition. If these were to be improved, the accuracy of the MPAN and APAN PAN-GC measurements could likely be improved further (e.g., to $\pm 5 \%$ ).

Stability of the sample flow rate was identified as a factor affecting the response factor in the PAN-GC. When the PANGC was operated with a slower sample flow rate (Table 5, Fig. 7b), the response factors were systematically greater than those when the PAN-GC was operated with a faster sample flow rate (Table 4, Fig. 7a), which lowered the number of molecules injected onto the column. In addition, the standard widths of the fits of the PAN peak were $\sim 20 \%$ larger (Fig. A1 in the Appendix), which suggests that the greater amount of air sampled led to a small amount of extra column band broadening.

\subsection{Comparison of PAN-GC with TD-CIMS data}

Zheng et al. (2011) and Mielke and Osthoff (2012) have documented some of the analytical challenges in using TDCIMS to make accurate measurements of the various PANs. In Abbotsford, the TD-CIMS data were compromised by the lack of a bona fide ${ }^{13} \mathrm{C}$-labeled PAN internal standard, but nevertheless showed excellent agreement with the PAN-GC PAN and PPN data, with slopes close to unity (Figs. 10 and 11). Part of the scatter may be due to temporal mismatches in the timing of the measurements. The general good agreement suggests that interference from acids as encountered in Pasadena (Mielke and Osthoff, 2012) played at best a minor role in the Abbotsford data set. Interference from peroxy acids (Phillips et al., 2013) was accounted for by subtracting the background measured in high NO concentrations.

The limits of detection for PAN and PPN for TDCIMS and PAN-GC (after the modifications for the FOSSILS campaign) are both in the single-digit pptv range, with the TD-CIMS having a much faster time response (Slusher et al., 2004; Turnipseed et al., 2006), which is an advantage when sampling rapidly changing air masses, for example, encountered from a moving platform such as an aircraft. For MPAN, however, PAN-GCs generally have the advantage, because TD-CIMS struggles with the quantification of MPAN in ambient air due to an interference from CPAN (Zheng et al., 2011) and a poor temperature-dependent response factor at $m / z 85$ (Table 9).

\section{Summary and conclusions}

A state-of-the-art PAN-GC has been described and calibrated using TD-CRDS for PAN, PPN MPAN, and APAN. The TDCRDS method is easily implemented and more tolerant to impurities than the conventionally used $\mathrm{NO}_{\mathrm{y}} \mathrm{CL}$ method, but is not entirely immune to PAN impurities co-generated during synthesis; hence, a preparatory GC will be constructed for future calibrations. Synthetic routes with acyl chlorides as starting reagents were found to generate $\mathrm{ClNO}_{2}$ and should not be used to generate PAN standards. PAN-GC is preferred over TD-CIMS in the quantification of MPAN in ambient air. 


\section{Appendix A}

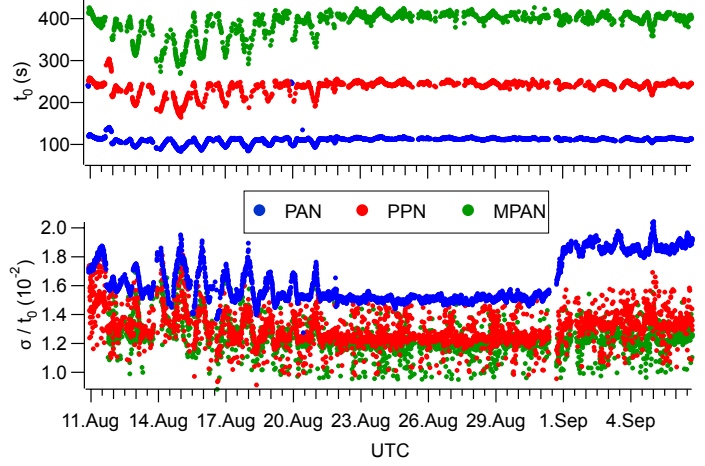

Figure A1. Stability of the PAN-GC retention times (top) and relative peak widths (bottom). The temperature inside the trailer was considerably more stable after 21 August, after an auxiliary air conditioning unit was installed.

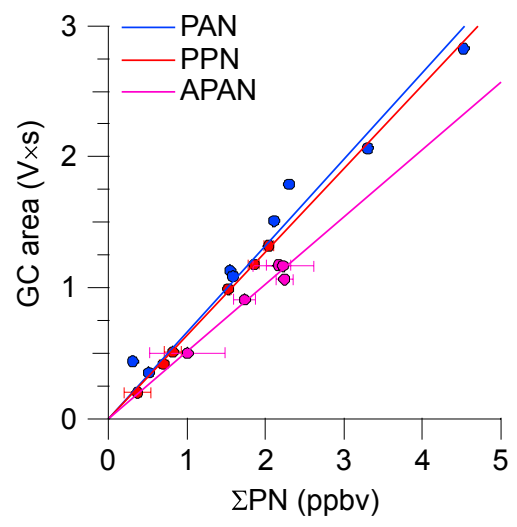

Figure A2. PAN-GC calibration plots for PAN, PPN, and APAN (post-FOSSILS).

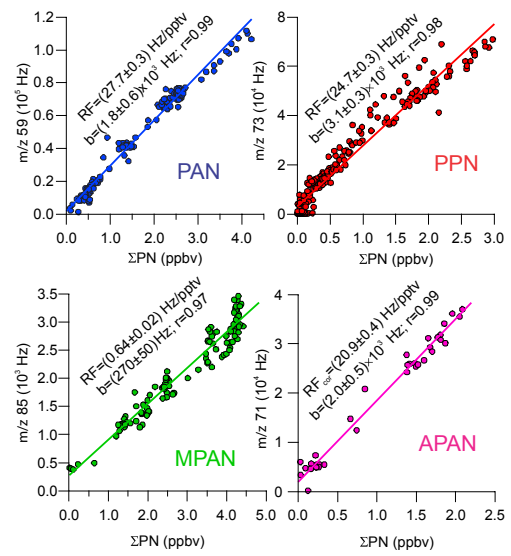

Figure A3. TD-CIMS calibration plots for PAN, PPN, MPAN, and APAN.
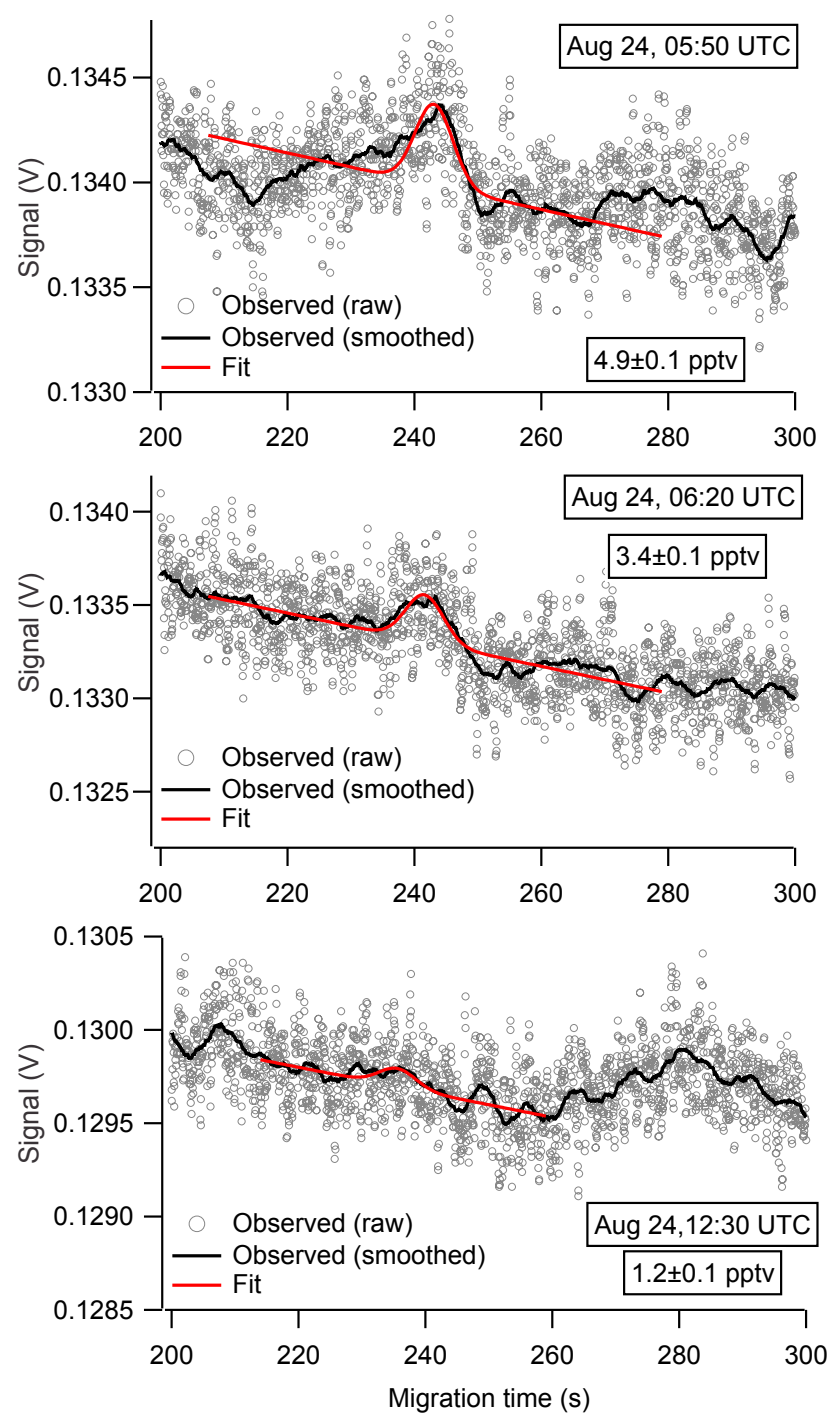

Figure A4. Sample chromatograms of PPN acquired on $24 \mathrm{Au}$ gust 2013 (analogous to those in Fig. 14) used to estimate the limit of detection for PPN. 

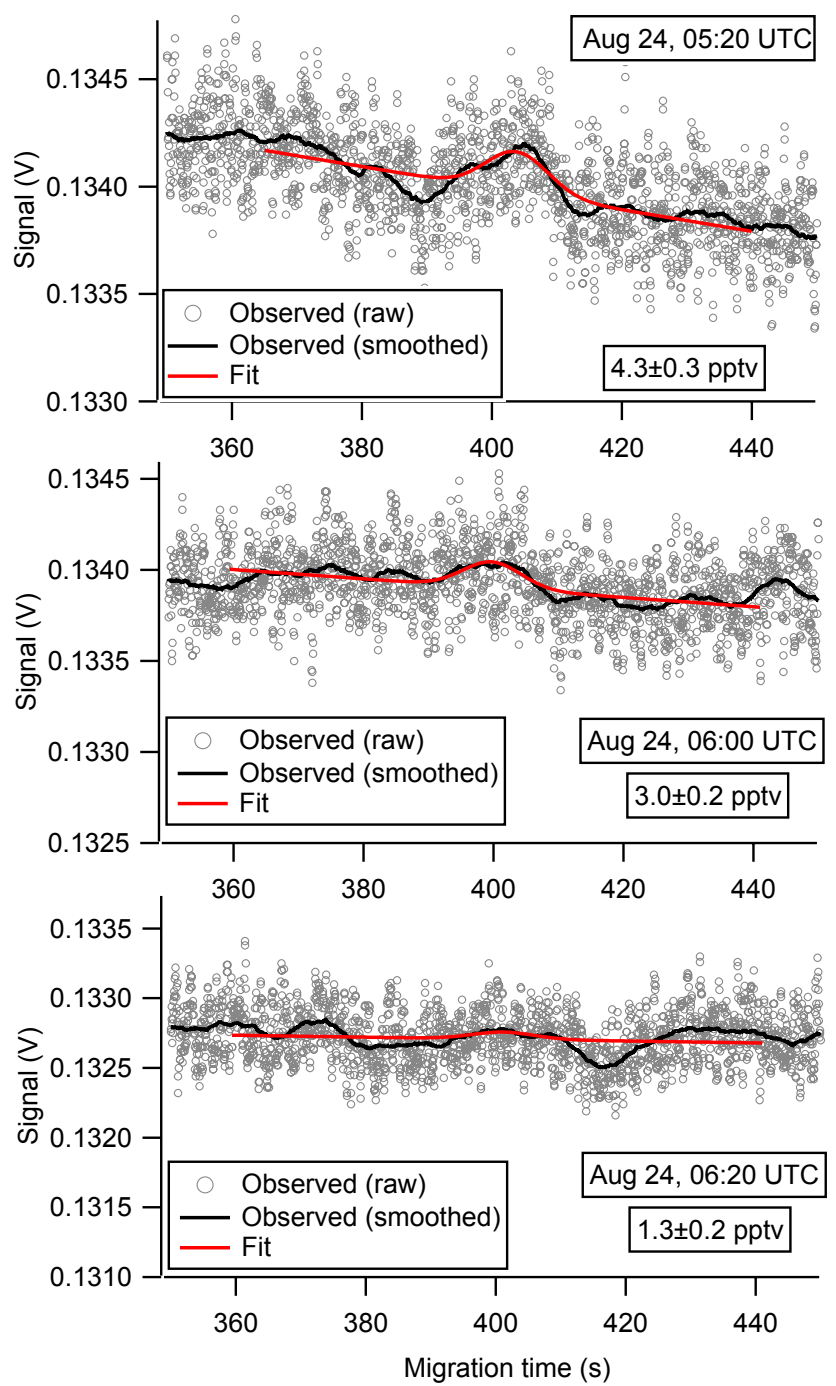

Figure A5. Sample chromatograms of MPAN acquired on 24 August 2013 (analogous to those in Fig. A4 in the Appendix and Fig. 15) used to estimate the limit of detection for MPAN. 
Acknowledgements. This project was undertaken with the financial support of the Government of Canada through the Federal Department of the Environment. Ce projet a été réalisé avec l'appui financier du Gouvernement du Canada agissant par l'entremise du ministère fédéral de l'Environnement. Partial funding for this work was provided by the Natural Sciences and Engineering Research Council of Canada (NSERC) in the form of operating (Discovery) and Research Tools and Instruments (RTI) grants. The Abbotsford field study was financially supported by a research grant from the Fraser Basin Council of British Columbia, and by Metro Vancouver. The authors thank J. Love and C. Berlinguette for a GC-ECD that was converted to a PAN-GC for this work, and the Open Access Authors Fund, Libraries and Cultural Resources, University of Calgary for covering the publication fees. H. D. Osthoff thanks James Roberts for useful discussions prior to undertaking this project and during the peer review stage.

Edited by: P. Di Carlo

\section{References}

Ainslie, B. and Steyn, D. G.: Spatiotemporal Trends in Episodic Ozone Pollution in the Lower Fraser Valley, British Columbia, in: Relation to Mesoscale Atmospheric Circulation Patterns and Emissions, J. Appl. Meteorol. Clim., 46, 1631-1644, doi:10.1175/JAM2547.1, 2007.

Altshuller, A. P.: PANs in the atmosphere, J. Air Waste Ma., 43, 1221-1230, doi:10.1080/1073161X.1993.10467199, 1993.

Alvarado, M. J., Logan, J. A., Mao, J., Apel, E., Riemer, D., Blake, D., Cohen, R. C., Min, K.-E., Perring, A. E., Browne, E. C., Wooldridge, P. J., Diskin, G. S., Sachse, G. W., Fuelberg, H., Sessions, W. R., Harrigan, D. L., Huey, G., Liao, J., Case-Hanks, A., Jimenez, J. L., Cubison, M. J., Vay, S. A., Weinheimer, A. J., Knapp, D. J., Montzka, D. D., Flocke, F. M., Pollack, I. B., Wennberg, P. O., Kurten, A., Crounse, J., Clair, J. M. St., Wisthaler, A., Mikoviny, T., Yantosca, R. M., Carouge, C. C., and Le Sager, P.: Nitrogen oxides and PAN in plumes from boreal fires during ARCTAS-B and their impact on ozone: an integrated analysis of aircraft and satellite observations, Atmos. Chem. Phys., 10, 9739-9760, doi:10.5194/acp-10-9739-2010, 2010.

Behnke, W., George, C., Scheer, V., and Zetzsch, C.: Production and decay of $\mathrm{ClNO}_{2}$, from the reaction of gaseous $\mathrm{N}_{2} \mathrm{O}_{5}$ with $\mathrm{NaCl}$ solution: Bulk and aerosol experiments, J. Geophys. Res., 102, 3795-3804, doi:10.1029/96JD03057, 1997.

Bertman, S. B. and Roberts, J. M.: A PAN analog from isoprene photooxidation, Geophys. Res. Lett., 18, 1461-1464, doi:10.1029/91g101852, 1991.

Blanchard, P., Shepson, P. B., So, K. W., Schiff, H. I., Bottenheim, J. W., Gallant, A. J., Drummond, J. W., and Wong, P.: A comparison of calibration and measurement techniques for gas chromatographic determination of atmospheric peroxyacetyl nitrate (PAN), Atmos. Environ., 24, 2839-2846, doi:10.1016/09601686(90)90171-I, 1990.

Darley, E. F., Kettner, K. A., and Stephens, E. R.: Analysis of Peroxyacyl Nitrates by Gas Chromatography with Electron Capture Detection, Anal. Chem., 35, 589-591, doi:10.1021/ac60197a028, 1963.

Day, D. A., Wooldridge, P. J., Dillon, M. B., Thornton, J. A., and Cohen, R. C.: A thermal dissociation laser-induced fluo- rescence instrument for in situ detection of $\mathrm{NO}_{2}$, peroxy nitrates, alkyl nitrates, and $\mathrm{HNO}_{3}$, J. Geophys. Res., 107, 4046, doi:10.1029/2001JD000779, 2002.

Emrich, M. and Warneck, P.: Photodissociation of acetone in air: Dependence on pressure and wavelength. Behavior of the excited singlet state, J. Phys. Chem. A, 104, 9436-9442, doi:10.1021/jp001873i, 2000.

Everest, M. A. and Atkinson, D. B.: Discrete sums for the rapid determination of exponential decay constants, Rev. Sci. Instrum., 79, 023108-023109, doi:10.1063/1.2839918, 2008.

Fischer, E. V., Jaffe, D. A., Reidmiller, D. R., and Jaegle, L.: Meteorological controls on observed peroxyacetyl nitrate at Mount Bachelor during the spring of 2008, J. Geophys. Res., 115, D03302, doi:10.1029/2009JD012776, 2010.

Flocke, F. M., Weinheimer, A. J., Swanson, A. L., Roberts, J. M., Schmitt, R., and Shertz, S.: On the measurement of PANs by gas chromatography and electron capture detection, J. Atmos. Chem., 52, 19-43, doi:10.1007/s10874-005-6772-0, 2005.

Furgeson, A., Mielke, L. H., Paul, D., and Osthoff, H. D.: A photochemical source of peroxypropionic and peroxyisobutanoic nitric anhydride, Atmos. Environ., 45, 5025-5032, doi:10.1016/j.atmosenv.2011.03.072, 2011.

Gaffney, J. S., Fajer, R., and Senum, G. I.: An improved procedure for high-purity gaseous peroxyacyl nitrate production - use of heavy lipid solvents, Atmos. Environ., 18, 215-218, doi:10.1016/0004-6981(84)90245-2, 1984.

Grosjean, D., Fung, K., Collins, J., Harrison, J., and Breitung, E.: Portable generator for on-site calibration of peroxyacetyl nitrate analyzers, Anal. Chem., 56, 569-573, doi:10.1021/ac00267a059, 1984.

Grosjean, D., Williams, E. L., and Grosjean, E.: Atmospheric chemistry of isoprene and of its carbonyl products, Environ. Sci. Technol., 27, 830-840, doi:10.1021/es00042a004, 1993a.

Grosjean, D., Williams, E. L., and Grosjean, E.: Peroxyacyl nitrates at southern California mountain forest locations, Environ. Sci. Technol., 27, 110-121, doi:10.1021/es00038a011, 1993b.

Grosjean, D., Grosjean, E., and Williams, E. L.: Thermal decomposition of PAN, PPN and vinyl-PAN, J. Air Waste Ma., 44, 391396, doi:10.1080/1073161X.1994.10467260, 1994.

Hansel, A. and Wisthaler, A.: A method for real-time detection of PAN, PPN and MPAN in ambient air, Geophys. Res. Lett., 27, 895-898, doi:10.1029/1999GL010989, 2000.

Hastie, D. R., Gray, J., Langford, V. S., Maclagan, R., Milligan, D. B., and McEwan, M. J.: Real-time measurement of peroxyacetyl nitrate using selected ion flow tube mass spectrometry, Rapid Commun. Mass Sp., 24, 343-348, doi:10.1002/rcm.4400, 2010.

Horvath, S. M., Bedi, J. F., and Drechslerparks, D. M.: Effects of peroxyacetyl nitrate alone and in combination with ozone in healthy-young women, J. Air Pollut. Control Assoc., 36, 265270, doi:10.1080/00022470.1986.10466067, 1986.

Kirchner, F., Mayer-Figge, A., Zabel, F., and Becker, K. H.: Thermal stability of Peroxynitrates, Internat. J. Chem. Kin., 31, 127-144, doi:10.1002/(SICI)1097-4601(1999)31:2<127::AIDKIN6>3.0.CO;2-L, 1999.

Kleindienst, T. E.: Recent developments in the chemistry and biology of peroxyacetyl nitrate, Res. Chem. Intermed., 20, 335-384 doi:10.1163/156856794X00379, 1994. 
LaFranchi, B. W., Wolfe, G. M., Thornton, J. A., Harrold, S. A., Browne, E. C., Min, K. E., Wooldridge, P. J., Gilman, J. B., Kuster, W. C., Goldan, P. D., de Gouw, J. A., McKay, M., Goldstein, A. H., Ren, X., Mao, J., and Cohen, R. C.: Closing the peroxy acetyl nitrate budget: observations of acyl peroxy nitrates (PAN, PPN, and MPAN) during BEARPEX 2007, Atmos. Chem. Phys., 9, 7623-7641, doi:10.5194/acp-9-7623-2009, 2009.

Marley, N. A., Gaffney, J. S., White, R. V., Rodriguez-Cuadra, L., Herndon, S. E., Dunlea, E., Volkamer, R. M., Molina, L. T., and Molina, M. J.: Fast gas chromatography with luminol chemiluminescence detection for the simultaneous determination of nitrogen dioxide and peroxyacetyl nitrate in the atmosphere, Rev. Sci. Instrum., 75, 4595-4605, doi:10.1063/1.1805271, 2004.

McNeill, V. F., Patterson, J., Wolfe, G. M., and Thornton, J. A.: The effect of varying levels of surfactant on the reactive uptake of $\mathrm{N}_{2} \mathrm{O}_{5}$ to aqueous aerosol, Atmos. Chem. Phys., 6, 1635-1644, doi:10.5194/acp-6-1635-2006, 2006.

Mielke, L. H. and Osthoff, H. D.: On quantitative measurements of peroxycarboxylic nitric anhydride mixing ratios by thermal dissociation chemical ionization mass spectrometry, Int. J. Mass Spectrom., 310, 1-9, doi:10.1016/j.ijms.2011.10.005, 2012.

Mielke, L. H., Furgeson, A., and Osthoff, H. D.: Observation of $\mathrm{ClNO}_{2}$ in a mid-continental urban environment, Environ. Sci. Technol., 45, 8889-8896, doi:10.1021/es201955u, 2011.

Mielke, L. H., Stutz, J., Tsai, C., Hurlock, S. C., Roberts, J. M., Veres, P. R., Froyd, K. D., Hayes, P. L., Cubison, M. J., Jimenez, J. L., Washenfelder, R. A., Young, C. J., Gilman, J. B., de Gouw, J. A., Flynn, J. H., Grossberg, N., Lefer, B. L., Liu, J., Weber, R. J., and Osthoff, H. D.: Heterogeneous formation of nitryl chloride and its role as a nocturnal $\mathrm{NO}_{\mathrm{x}}$ reservoir species during CalNex-LA 2010, J. Geophys. Res., 118, 10638-10652, doi:10.1002/jgrd.50783, 2013.

Mills, G. P., Sturges, W. T., Salmon, R. A., Bauguitte, S. J.-B., Read, K. A., and Bandy, B. J.: Seasonal variation of peroxyacetylnitrate (PAN) in coastal Antarctica measured with a new instrument for the detection of sub-part per trillion mixing ratios of PAN, Atmos. Chem. Phys., 7, 4589-4599, doi:10.5194/acp-7-4589-2007, 2007.

Nikitas, C., Clemitshaw, K. C., Oram, D. E., and Penkett, S. A.: Measurements of PAN in the polluted boundary layer and free troposphere using a luminol- $\mathrm{NO}_{2}$ detector combined with a thermal converter, J. Atmos. Chem., 28, 339-359, doi:10.1023/a:1005898017520, 1997.

Nouaime, G., Bertman, S. B., Seaver, C., Elyea, D., Huang, H., Shepson, P. B., Starn, T. K., Riemer, D. D., Zika, R. G., and Olszyna, K.: Sequential oxidation products from tropospheric isoprene chemistry: MACR and MPAN at a $\mathrm{NO}_{\mathrm{x}}$-rich forest environment in the southeastern United States, J. Geophys. Res., 103, 22463-22471, doi:10.1029/98JD00320, 1998.

Odame-Ankrah, C. A. and Osthoff, H. D.: A compact diode laser cavity ring-down spectrometer for atmospheric measurements of $\mathrm{NO}_{3}$ and $\mathrm{N}_{2} \mathrm{O}_{5}$ with automated zeroing and calibration, Appl. Spectrosc., 65, 1260-1268, doi:10.1366/11-06384, 2011.

Osthoff, H. D., Roberts, J. M., Ravishankara, A. R., Williams, E. J., Lerner, B. M., Sommariva, R., Bates, T. S., Coffman, D., Quinn, P. K., Stark, H., Burkholder, J. B., Talukdar, R. K., Meagher, J., Fehsenfeld, F. C., and Brown, S. S.: High levels of nitryl chloride in the polluted subtropical marine boundary layer, Nat. Geosci., 1, 324-328, doi:10.1038/ngeo177, 2008.
Pandey Deolal, S., Staehelin, J., Brunner, D., Cui, J., Steinbacher, M., Zellweger, C., Henne, S., and Vollmer, M. K.: Transport of PAN and $\mathrm{NO}_{\mathrm{y}}$ from different source regions to the Swiss high alpine site Jungfraujoch, Atmos. Environ., 64, 103-115, doi:10.1016/j.atmosenv.2012.08.021, 2013.

Pätz, H.-W., Lerner, A., Houben, N., and Volz-Thomas, A.: Validation of a new method for the calibration of peroxy acetyl nitrate (PAN)-analyzers, Gefahrstoffe Reinhaltung Der Luft, 62, 215219, 2002.

Paul, D. and Osthoff, H. D.: Absolute Measurements of Total Peroxy Nitrate Mixing Ratios by Thermal Dissociation Blue Diode Laser Cavity Ring-Down Spectroscopy, Anal. Chem., 82, 66956703, doi:10.1021/ac101441z, 2010.

Paul, D., Furgeson, A., and Osthoff, H. D.: Measurement of total alkyl and peroxy nitrates by thermal decomposition cavity ring-down spectroscopy, Rev. Sci. Instrum., 80, 114101, doi:10.1063/1.3258204, 2009.

Phillips, G. J., Pouvesle, N., Thieser, J., Schuster, G., Axinte, R., Fischer, H., Williams, J., Lelieveld, J., and Crowley, J. N.: Peroxyacetyl nitrate (PAN) and peroxyacetic acid (PAA) measurements by iodide chemical ionisation mass spectrometry: first analysis of results in the boreal forest and implications for the measurement of PAN fluxes, Atmos. Chem. Phys., 13, 11291139, doi:10.5194/acp-13-1129-2013, 2013.

Roberts, J. M.: The atmospheric chemistry of organic nitrates, Atmos. Environ. A, 24, 243-287, doi:10.1016/09601686(90)90108-Y, 1990.

Roberts, J. M.: PAN and Related Compounds, in: Volatile Organic Compounds in the Atmosphere, edited by: Koppmann, R., Blackwell Publishing, Oxford, UK, 221-268, 2007.

Roberts, J. M., Williams, J., Baumann, K., Buhr, M. P., Goldan, P. D., Holloway, J., Hubler, G., Kuster, W. C., McKeen, S. A., Ryerson, T. B., Trainer, M., Williams, E. J., Fehsenfeld, F. C., Bertman, S. B., Nouaime, G., Seaver, C., Grodzinsky, G., Rodgers, M., and Young, V. L.: Measurements of PAN, PPN, and MPAN made during the 1994 and 1995 Nashville Intensives of the Southern Oxidant Study: Implications for regional ozone production from biogenic hydrocarbons, J. Geophys. Res., 103, 22473 22490, doi:10.1029/98JD01637, 1998.

Roberts, J. M., Flocke, F., Weinheimer, A., Tanimoto, H., Jobson, B. J., Riemer, D., Apel, E., Atlas, E., Donnelly, S., Stroud, V., Johnson, K., Weaver, R., and Fehsenfeld, F. C.: Observations of APAN during TexAQS 2000, Geophys. Res. Lett., 28, 41954198, doi:10.1029/2001GL013466, 2001.

Roberts, J. M., Flocke, F., Stroud, C. A., Hereid, D., Williams, E., Fehsenfeld, F., Brune, W., Martinez, M., and Harder, H.: Groundbased measurements of peroxycarboxylic nitric anhydrides (PANs) during the 1999 Southern Oxidants Study Nashville Intensive, J. Geophys. Res., 107, 4554, doi:10.1029/2001jd000947, 2002.

Roberts, J. M., Jobson, B. T., Kuster, W., Goldan, P., Murphy, P., Williams, E., Frost, G., Riemer, D., Apel, E., Stroud, C., Wiedinmyer, C., and Fehsenfeld, F.: An examination of the chemistry of peroxycarboxylic nitric anhydrides and related volatile organic compounds during Texas Air Quality Study 2000 using ground-based measurements, J. Geophys. Res.-Atmos., 108, 4495, doi:10.1029/2003jd003383, 2003.

Roberts, J. M., Marchewka, M., Bertman, S. B., Goldan, P., Kuster, W., de Gouw, J., Warneke, C., Williams, E., Lerner, B., Mur- 
phy, P., Apel, E., and Fehsenfeld, F. C.: Analysis of the isoprene chemistry observed during the New England Air Quality Study (NEAQS) 2002 intensive experiment, J. Geophys. Res., 111, D23S12, doi:10.1029/2006JD007570, 2006.

Roberts, J. M., Marchewka, M., Bertman, S. B., Sommariva, R., Warneke, C., de Gouw, J., Kuster, W., Goldan, P., Williams, E., Lerner, B. M., Murphy, P., and Fehsenfeld, F. C.: Measurements of PANs during the New England Air Quality Study 2002, J. Geophys. Res.-Atmos., 112, D20306, doi:10.1029/2007jd008667, 2007.

Roumelis, N. and Glavas, S.: Decomposition of peroxyacetyl nitrate and peroxypropionyl nitrate during gas chromatographic determination with a wide-bore capillary and two packed columns, Anal. Chem., 61, 2731-2734, doi:10.1021/ac00199a010, 1989.

Sanagi, M. M., Ling, S. L., Nasir, Z., Hermawan, D., Ibrahim, W. A. W., and Abu Naim, A.: Comparison of Signal-to-Noise, Blank Determination, and Linear Regression Methods for the Estimation of Detection and Quantification Limits for Volatile Organic Compounds by Gas Chromatography, J. AOAC Int., 92, 18331838, 2009.

Schrimpf, W., Müller, K. P., Johnen, F. J., Lienaerts, K., and Rudolph, J.: An optimized method for airborne peroxyacetyl nitrate (PAN) measurements, J. Atmos. Chem., 22, 303-317, doi:10.1007/BF00696640, 1995.

Slusher, D. L., Huey, L. G., Tanner, D. J., Flocke, F. M., and Roberts, J. M.: A thermal dissociation-chemical ionization mass spectrometry (TD-CIMS) technique for the simultaneous measurement of peroxyacyl nitrates and dinitrogen pentoxide, J. Geophys. Res., 109, D19315, doi:10.1029/2004JD004670, 2004.

Stroud, C., Madronich, S., Atlas, E., Ridley, B., Flocke, F., Weinheimer, A., Talbot, B., Fried, A., Wert, B., Shetter, R., Lefer, B., Coffey, M., Heikes, B., and Blake, D.: Photochemistry in the arctic free troposphere: $\mathrm{NO}_{\mathrm{x}}$ budget and the role of odd nitrogen reservoir recycling, Atmos. Environ., 37, 3351-3364, doi:10.1016/S1352-2310(03)00353-4, 2003.

Taha, Y. M., Odame-Ankrah, C. A., and Osthoff, H. D.: Real-time vapor detection of nitroaromatic explosives by catalytic thermal dissociation blue diode laser cavity ring-down spectroscopy, Chem. Phys. Lett., 582, 15-20, doi:10.1016/j.cplett.2013.07.040, 2013.

Tanimoto, H. and Akimoto, H.: A new peroxycarboxylic nitric anhydride identified in the atmosphere: $\mathrm{CH}_{2}=\mathrm{CHC}(\mathrm{O}) \mathrm{OONO}_{2}$ (APAN), Geophys. Res. Lett., 28, 2831-2834, doi:10.1029/2001GL012998, 2001.

Tanimoto, H., Hirokawa, J., Kajii, Y., and Akimoto, H.: A new measurement technique of peroxyacetyl nitrate at parts per trillion by volume levels: Gas chromatography/negative ion chemical ionization mass spectrometry, J. Geophys. Res., 104, 21343-21354, doi:10.1029/1999JD900345, 1999.

Thaler, R. D., Mielke, L. H., and Osthoff, H. D.: Quantification of Nitryl Chloride at Part Per Trillion Mixing Ratios by Thermal Dissociation Cavity Ring-Down Spectroscopy, Anal. Chem., 83, 2761-2766, doi:10.1021/ac200055z, 2011.

Thornberry, T., Carroll, M. A., Keeler, G. J., Sillman, S., Bertman, S. B., Pippin, M. R., Ostling, K., Grossenbacher, J. W., Shepson, P. B., Cooper, O. R., Moody, J. L., and Stockwell, W. R.: Observations of reactive oxidized nitrogen and speciation of $\mathrm{NO}_{\mathrm{y}}$ during the PROPHET summer 1998 intensive, J. Geophys. Res., 106, 24359-24386, doi:10.1029/2000JD900760, 2001.
Turnipseed, A. A., Huey, L. G., Nemitz, E., Stickel, R., Higgs, J., Tanner, D. J., Slusher, D. L., Sparks, J. P., Flocke, F., and Guenther, A.: Eddy covariance fluxes of peroxyacetyl nitrates (PANs) and $\mathrm{NO}_{\mathrm{y}}$ to a coniferous forest, J. Geophys. Res., 111, D09304, doi:10.1029/2005JD006631, 2006.

Vingarzan, R. and Li, S. M.: The Pacific 2001 Air Quality Study synthesis of findings and policy implications, Atmos. Environ., 40, 2637-2649, doi:10.1016/j.atmosenv.2005.09.083, 2006.

Volz-Thomas, A., Xueref, I., and Schmitt, R.: An automatic gas chromatograph and calibration system for ambient measurements of PAN and PPN, Environ. Sci. Poll. Res., 9, 72-76, 2002.

Warneck, P. and Zerbach, T.: Synthesis of peroxyacetyl nitrate in air by acetone photolysis, Environ. Sci. Technol., 26, 74-79, doi:10.1021/es00025a005, 1992.

Williams, E. L., Grosjean, E., and Grosjean, D.: Ambient levels of the peroxyacyl nitrates PAN, PPN and MPAN in Atlanta, Georgia, J. Air Waste Ma., 43, 873-879, doi:10.1080/1073161X.1993.10467170, 1993.

Williams, J., Roberts, J. M., Bertman, S. B., Stroud, C. A., Fehsenfeld, F. C., Baumann, K., Buhr, M. P., Knapp, K., Murphy, P C., Nowick, M., and Williams, E. J.: A method for the airborne measurement of PAN, PPN, and MPAN, J. Geophys. Res., 105, 28943-28960, doi:10.1029/2000JD900373, 2000.

Wolfe, G. M., Thornton, J. A., McNeill, V. F., Jaffe, D. A., Reidmiller, D., Chand, D., Smith, J., Swartzendruber, P., Flocke, F., and Zheng, W.: Influence of trans-Pacific pollution transport on acyl peroxy nitrate abundances and speciation at Mount Bachelor Observatory during INTEX-B, Atmos. Chem. Phys., 7, 53095325, doi:10.5194/acp-7-5309-2007, 2007.

Wolfe, G. M., Thornton, J. A., Yatavelli, R. L. N., McKay, M., Goldstein, A. H., LaFranchi, B., Min, K.-E., and Cohen, R. C.: Eddy covariance fluxes of acyl peroxy nitrates (PAN, PPN and MPAN) above a Ponderosa pine forest, Atmos. Chem. Phys., 9, 615-634, doi:10.5194/acp-9-615-2009, 2009.

Wooldridge, P. J., Perring, A. E., Bertram, T. H., Flocke, F. M., Roberts, J. M., Singh, H. B., Huey, L. G., Thornton, J. A., Wolfe, G. M., Murphy, J. G., Fry, J. L., Rollins, A. W., LaFranchi, B. W., and Cohen, R. C.: Total Peroxy Nitrates ( $\Sigma$ PNs) in the atmosphere: the Thermal Dissociation-Laser Induced Fluorescence (TD-LIF) technique and comparisons to speciated PAN measurements, Atmos. Meas. Tech., 3, 593-607, doi:10.5194/amt-3-5932010, 2010.

Zhang, G., Mu, Y. J., Liu, J. F., and Mellouki, A.: Direct and simultaneous determination of trace-level carbon tetrachloride, peroxyacetyl nitrate, and peroxypropionyl nitrate using gas chromatography-electron capture detection, J. Chromatogr. A, 1266, 110-115, doi:10.1016/j.chroma.2012.09.092, 2012.

Zhang, J. M., Wang, T., Ding, A. J., Zhou, X. H., Xue, L. K., Poon, C. N., Wu, W. S., Gao, J., Zuo, H. C., Chen, J. M., Zhang, X. C., and Fan, S. J.: Continuous measurement of peroxyacetyl nitrate (PAN) in suburban and remote areas of western China, Atmos. Environ., 43, 228-237, doi:10.1016/j.atmosenv.2008.09.070, 2009.

Zheng, W., Flocke, F. M., Tyndall, G. S., Swanson, A., Orlando, J. J., Roberts, J. M., Huey, L. G., and Tanner, D. J.: Characterization of a thermal decomposition chemical ionization mass spectrometer for the measurement of peroxy acyl nitrates (PANs) in the atmosphere, Atmos. Chem. Phys., 11, 6529-6547, doi:10.5194/acp-11-6529-2011, 2011. 